\title{
RETHINKING THE REGULATION OF COERCIVE CREDITOR REMEDIES
}

\author{
Robert E. Scott*
}

The phenomenal growth of personal installment credit over the past forty years ${ }^{1}$ has generated inevitable pressures for regulatory reform of consumer credit markets. Much of the impetus for consumer protection has stemmed from the perceived abuses that mark the process of coercive collection upon default. Some of these abuses have been identified, quite properly, as the sort of deceptive or fraudulent practices often associated with industries experiencing rapid growth. But other creditor remedies, though troublesome to many observers, cannot be as easily characterized. For example, many critics have challenged the common practice of self-help repossession and resale of consumer goods by secured creditors. Repossession belongs to a family of contractually created remedies, including wage assignments, confessions of judgment and waivers of exemption from execution, that is often characterized as coercive. Creditors are assumed to use the threat of these self-enforcing remedial options to coerce defaulting debtors to agree to one-sided settlements.

The concept of "lost value" underlies the objection to most coercive creditor remedies. ${ }^{2}$ Creditors often pursue coercive collection in cases in which the benefits to the creditor appear to be significantly less than the costs imposed on the debtor. The punitive aspect of this de-

* Lewis F. Powell, Jr. Professor of Law and Member, Center for Advanced Studies, University of Virginia.

I would like to thank Ken Abraham, Richard Alderman, Frank Buckley, Robert Cooter, Tom Jackson, John Jeffries, Saul Levmore, John Monahan, Alan Schwartz, Paul Stephan, Bill Stuntz, Michael Trebilcock, William Whitford and the participants in workshops at McGill University, the University of Virginia and Columbia University for their helpful comments on earlier versions of this Article.

1. From 1950 to 1971 , personal installment debt grew by $500 \%$. National Commission on Consumer Finance, Consumer Credit in the United States 5-21 (1972). This pattern has continued to the present. Thus, in 1971 outstanding consumer installment debt totalled $\$ 105.7$ billion. At the end of 1981 , total consumer installment debt amounted to $\$ 333.4$ billion. National Consumer Finance Association, 1982 Finance Fact Yearbook 41.

2. In this Article, I use "coercive collection" and "coercive creditor remedies" to refer only to those self-enforcing remedies that are, at least to some extent, prior to and independent of the alternative process of postjudgment execution. To be sure, all creditor remedies, including postjudgment levy and execution, are coercive. But the fear is that certain self-enforcing remedies are much more coercive and thus more harmful to debtors than any corresponding benefits to creditors would justify. The concerns about the undesirable effects of coercion are less acute in the case of postjudgment execution because the state-supervised enforcement process embodies procedural safeguards that moderate unwarranted and unfair collection behavior. This rhetorical limitation should not obscure the fact that many of the same arguments for and against regulating these remedial options might be applied to postjudgment collection. Nevertheless, self-en- 
struction of value forms the primary justification for the recently promulgated Federal Trade Commission Credit Practices Rule, ${ }^{\mathbf{3}}$ which prohibits such common credit terms as blanket security interests in household goods and contractual wage assignments. ${ }^{4}$ Indeed, the lost value assumption supplied the crucial argument that the benefits from regulating creditor remedies were far greater than the costs: since the prohibited practices are believed to cause more injury to consumers than corresponding benefits to creditors, prohibition should have only a modest effect on the price or the supply of installment credit. $^{5}$

The lost-value thesis has also sparked a vigorous academic debate. William Whitford, developing ideas first suggested by Arthur Leff, has argued that information asymmetries lead to a systematic bargaining impasse between debtors and creditors. ${ }^{6}$ This impasse results either in repossessions that destroy value unnecessarily or in coercive threats that induce debtors to accept unfavorable settlements. ${ }^{7}$ Alan Schwartz, on the other hand, suggests that lost value is largely a perceptual illusion fueled by would-be regulators' ignorance of the actual operation of credit markets. ${ }^{8}$ While conceding the possibility that creditors may

forcing remedies are a useful and distinct paradigm for assessing the relationship between consumer debtors and their creditors.

A further problem with grouping the various self-enforcing remedies together is that this classification tends to blur the fact that each of these remedies is different in important respects. Ultimately, therefore, any policy analysis that points to specific legal reform must pay greater attention to these differences. My purpose in writing this Article is to encourage such a reexamination by focusing on previously neglected functions of these coercive collection practices. Moreover, while these remedies have different characteristics, there is substantial evidence that they function as substitutes for one another. See infra note 26.

3. FTC Credit Practices Rule, 16 C.F.R. § 444.1-.5 (1988). The rule was upheld in American Fin. Servs. Ass'n v. FTC, 767 F.2d 957 (D.C. Cir. 1985), cert. denied, 475 U.S. 1011 (1986).

4. Prior to the promulgation of the Federal Trade Commission ("FTC") rule, selfenforcing remedies were used extensively in installment loan contracts. For example, in 1975, wage-assignment clauses appeared in $73.2 \%$ of the installment loans made by licensed lenders in New York. FTC, Trade Regulation Rule; Credit Practices, 49 Fed. Reg. 7740, 7757 (1984) [hereinafter FTC Rule]. Such agreements were also widely employed by small loan and finance companies in California, Illinois and Michigan. Id. The use of blanket security interests in household goods was even more widespread. Household-goods clauses were used in a majority of finance company loan contracts. Id. at 7762 . In addition, banks, credit unions and occasionally savings and loan associations took such security interests. Id.

5. Id. at 7779-81.

6. Whitford, The Appropriate Role of Security Interests in Consumer Transactions, 7 Cardozo L. Rev. 959, 961-66 (1986) [hereinafter Whitford, The Appropriate Role of Security Interests]; Whitford, A Critique of the Consumer Credit Collection System, 1979 Wis. L. Rev. 1047, 1106-08 [hereinafter Whitford, A Critique]; see Leff, Injury, Ignorance and Spite-The Dynamics of Coercive Collection, 80 Yale L.J. 1 (1970).

7. See Whitford, The Appropriate Role of Security Interests, supra note 6, at 964-65.

8. Schwartz, The Enforceability of Security Interests in Consumer Goods, 26 J.L. \& Econ. 117, 139-48 (1983). 
threaten coercive action to induce repayment, Schwartz argues that they will do so only when the action represents the cost-minimizing collection option. ${ }^{9}$

While this debate has resulted in sharp disagreements and divergent normative recommendations, the participants nevertheless proceed from shared assumptions about the function of coercive creditor remedies. The conventional assumption is that self-enforcing remedies are designed principally (if not exclusively) to enhance the creditor's prospect of repayment in the event of default. Thus, the debate continues over whether settlements induced by the threat of remedial action are normatively undesirable, whether repossession destroys value or whether regulation will motivate creditors to adopt more benign substitutes. ${ }^{10}$ What has gone entirely unnoticed, however, is the possibility that these remedial options also play a substantial role in the infinitely larger class of consumer transactions in which the debtor does not default. ${ }^{11}$

This Article suggests that the conventional analysis is premised on an unduly narrow conception of the function of creditor remedies and of the debtor-creditor conflicts that they ameliorate. A single-minded focus on the postdefault implications of coercive collection invariably characterizes the debtor and creditor as locked in a zero-sum conflict situation. The prohibition of certain remedies thus is seen solely in terms of cost to the creditor, offset by corresponding gains for the debtor. But if the relationship is viewed ex ante, debtor and creditor are actually participants in a cooperative bargaining opportunity-an interaction in which both parties can mutually benefit from cooperation, but in which each confronts the risk of defection by the other. Thus conceived, the regulation of creditor remedies may have the perverse effect of eliminating the very mechanisms used to ensure that the parties will exploit fully their common interests.

Part I of the Article develops a conceptual framework for reevaluating the function of various creditor remedies. A bargaining theory approach suggests that many self-enforcing remedies may have a valuable regulatory function, one that enables the parties to achieve mutually advantageous objectives. From this $e x$ ante perspective, the lost-value potential inherent in certain remedial options is recharacterized as a

9. Id. at 151-52.

10. For a recent, and thoughtful, example of the conventional argument, see Braucher, Defining Unfairness: Empathy and Economic Analysis at the Federal Trade Commission, 68 B.U.L. Rev. 349 (1988).

11. By any measure, default is not a common experience in consumer credit transactions. Data on automobile loans, which constitute $37.9 \%$ of all installment credit, indicates a yearly default rate that fluctuates between $3 \%$ and $6 \%$. American Bankers Association Installment Lending Division, Delinquency Rates on Bank Installment Loans, 1982. Testimony before the FTC indicated that at any given time about $7 \%$ of finance company accounts were past due. Creditors other than finance companies have even lower delinquency rates. See FTC Rule, supra note 4, at 7748 . 
modern version of an ancient institution, the exchange of hostages. The paradox of these collection mechanisms is that the greater the potential lost value, the more effective the particular mechanism is in advancing the parties' cooperative goals. To be sure, once a debtor defaults, the various collection options may appear to exacerbate costly conflicts. In fact, however, the coercive postdefault environment is caused by systematic information deficits and is largely independent of the remedial options available to creditors.

Part II tests the validity of a bargaining theory approach to consumer credit transactions. The principal question is whether the patterns of interaction predicted by a cooperative bargaining model are actually observed in consumer credit relationships. The available data provide substantial support for the basic claims of this ex ante perspective. Nevertheless, the tentative state of the evidence suggests a further inquiry: do the implications of the model hold even after all of its assumptions are explicitly relaxed? Even in this more realistic setting, the ex ante perspective offers valuable insights into the nature and function of self-enforcing remedies.

Finally, Part III considers the normative implications of the bargaining theory approach. From this perspective, conventional marketfailure justifications for prohibiting self-enforcing remedies are, at best, problematic. The risk of systematic exploitation of consumer debtors is most acute in currently unregulated transactions, such as purchase money security interests in consumer durables. Moreover, disclosure and other methods of information exchange offer more promise for mitigating the undesirable effects of default. An alternative case for current regulation rests on a credit-rationing objective: prohibition may be designed to override the poor judgment of consumer debtors by metering the supply of installment credit. Such a risk-regarding rationale accepts the likely increase in the cost of credit in order to prevent systematic overcommitment by consumer debtors. But the ex ante approach also challenges the poor-judgment case for prohibition. It is simply perverse to prohibit commitments that restrain overconsumption on the ground that, given their free choice, consumer debtors will overconsume.

The only remaining case for the current scheme of regulation rests on the "superfairness" idea of distributional equity. The prohibition of creditor remedies does redistribute postdefault leverage from creditors to those debtors who default, even though debtors committed to repayment likely will bear much of the redistributional burden. Nevertheless, regulation reduces concentrated costs, whereas the unrestrained use of self-enforcing terms would produce only diffused gains. If diffused gains are weighted less in individuals' perceptions than concentrated losses, the parties may perceive the distribution as fair in the sense that no individual envies the postdistribution entitlements of any other. 
I conclude from this analysis that the prohibition of selected creditor remedies is unlikely to achieve the normative objective of reducing postdefault coercion. A cooperative bargaining model shows that the structural imperatives of the consumer credit transaction cannot be ignored. If the coercion associated with postdefault maneuvering is normatively undesirable, the most effective solution is to reduce the information deficits that motivate postdefault actions. Otherwise, selective regulation of particular terms inevitably will be trumped by the pressure for substitute enforcement mechanisms. On the other hand, if the process of coercive collection is intrinsically a "bad thing," then the culprit is the institution of consumer credit, not the self-enforcing terms parties use to attempt to maximize the benefits available from the relationship.

\section{A Cooperative Bargaining Theory of the Consumer Credit Transaction}

\section{A. The Regulation of Unfair Creditor Remedies}

1. A Brief History of the Lost Value Hypothesis. - The consumer credit industry has experienced rapid growth for over forty years. Growth industries are often characterized by fluid entry and exit of firms until a competitive equilibrium is reached. Meantime, these unstable conditions are a breeding ground for fraudulent and deceptive practices. It is not surprising, therefore, that policymakers, accustomed to responding to one quick-buck scheme after another, developed a presumption that the market for consumer credit was systematically, perhaps even irredeemably, flawed. ${ }^{12}$

As the consumer credit market stabilized, the incidence of fraud and deceptive practices declined. Thus, the regulatory focus shifted to a more subtle problem. Various self-enforcing remedies for default, though not facially deceptive or fraudulent, often appeared "unfair" or "coercive" when they were exercised. The injury to consumer debtors caused by self-help repossession, confessed judgments or wage assign-

12. The relevant protective law is both state and federal. These laws regulate the setting of permissible lending and credit charges, the disclosure of credit costs and credit terms and a wide range of credit practices deemed to be unfair. Perhaps the most important of these regulatory initiatives is the Consumer Credit Protection Act, 15 U.S.C. \$§ 1601-1693r (1982 \& Supp. IV 1986). In addition to requiring uniform disclosure of credit rates, the Act as amended regulates credit billings, consumer leases, garnishments, consumer credit reporting, equal credit opportunity and debt-collection practices. For a critical overview, see Landers \& Rohner, A Functional Analysis of Truth in Lending, 26 UCLA L. Rev. 711 (1979). The Uniform Consumer Credit Code (U.C.C.C.) also regulates the terms of credit contracts, including the definition of default, U.C.C.C. $\$ 5.109$ (1974), the prohibition of contractual wage assignments, id. $\S 3.305$, restrictions on blanket security interests, id. $\S \S 3.301-.302$, and restrictions on deficiency judgments, id. $\$ 5.103$. Various versions of the U.C.C.C. have been adopted in ten states. See generally A. Schwartz \& R. Scott, Commercial Transactions: Principles and Policies 832-41 (1982) (discussing the U.C.C.C.'s consumer protections). 
ments frequently seemed greater than the corresponding benefits to creditors. In many instances (automobile repossessions were only the clearest examples), it seemed as though the exercise of these remedies did not result in a straightforward transfer of property rights from defaulting debtors to creditors. Rather, resort to these remedial options resulted in excessive destruction or "loss" of value, frequently leaving debtors without the goods and with large deficiencies. ${ }^{13}$ Understandably, these losses were attributed to the deliberate or careless failure of creditors to maximize the returns from coercive collection.

In a pioneering paper, Arthur Leff shifted the debate from creditor misbehavior to the structural dynamics of the postdefault collection process. ${ }^{14}$ Leff argued that lost value was an inevitable by-product of the information asymmetries characteristic of the postdefault collection process. ${ }^{15}$ These asymmetries generate costly and coercive maneuvering by both parties-behavior that destroys the debtor's wealth without greatly helping the creditor. ${ }^{16}$

This lost-value premise formed the basis for a widely accepted hypothesis that both the threat and the exercise of self-help remedies would, absent legal intervention, lead to normatively undesirable coercion and exploitation of consumer debtors. The hypothesis was supported by several studies of automobile repossessions showing resales of repossessed automobiles at substantially less than book wholesale value. ${ }^{17}$ In response, a number of states enacted special legislation regulating self-enforcing remedies. Some states chose to ban deficiency judgments in certain sales transactions, ${ }^{18}$ while others limited the en-

13. Any contractual remedy that requires a transfer of assets from one party to another will cause the loss of value, since the transaction costs of effecting the transfer always will be positive. The argument, therefore, is that certain self-enforcing remedies destroy value gratuitously. Excessive value destruction may result because repossessing creditors do not maximize the returns from resales, debtors attach idiosyncratic value to the assets or enforcement causes debtors to suffer psychic or other consequential losses.

14. Leff, supra note 6 .

15. Id. at $42-46$.

16. Id. at $10-15$.

17. See Shuchman, Profit on Default: An Archival Study of Automobile Repossession and Resale, 22 Stan. L. Rev. 20 (1969); White, Consumer Repossessions and Deficiencies: New Perspectives from New Data, 23 B.C.L. Rev. 385 (1982); Note, Business as Usual: An Empirical Study of Automobile Deficiency Judgment Suits in the District of Columbia, 3 Conn. L. Rev. 511 (1971) [hereinafter Note, Business as Usual]; Note, I Can Get It for You Wholesale: The Lingering Problem of Automobile Deficiency Judgments, 27 Stan. L. Rev. 1081 (1975).

18. See, e.g., Cal. Civ. Code $\S 1812.5$ (West 1985) (banning deficiencies in all resales of repossessed goods); Ind. Code Ann. § 24-4.5-5-103 (Burns 1982) (banning deficiency in sales transactions when the sales price is below $\$ 1,000)$; Wash. Rev. Code Ann. tit. 62A, § 9-501(1) (1966 \& Supp. 1989) (banning deficiencies in all "purchase money security interests in consumer goods"). Similar restrictions exist in Alabama, Arizona, Colorado, Idaho, Oklahoma, Utah and Wyoming. See Schwartz, supra note 8, at 123 n.24. 
forcement of wage assignments, ${ }^{19}$ waivers of asset exemptions ${ }^{20}$ and confession of judgment clauses. ${ }^{21}$ Finally, in 1984 the Federal Trade Commission ("FTC") promulgated a Credit Practices Rule declaring most self-enforcing remedies "unfair" to consumers. ${ }^{22}$ The FTC relied specifically on the lost-value premise in banning contract terms providing for blanket security interests in household goods, ${ }^{23}$ wage assignments, waivers of asset exemptions and confessions of judgment. ${ }^{24}$

The FTC rule represents a significant expansion in the scale of regulation. While virtually every state previously had regulated some aspect of coercive collection, ${ }^{25}$ no state had prohibited the entire family of terms now banned by the FTC rule. Furthermore, the various state prohibitions did not seem to fall in any discernible pattern. In virtually every state, at least one of the now-prohibited contractual remedies was widely used, although the particular remedy of choice varied from state to state. ${ }^{26}$

19. See, e.g., Ala. Code $\S 8-5-21$ (a) (1975) (assignment of future wages void); Conn. Gen. Stat. Ann. $\S 52-361$ a(i) (West Supp. 1988) (assignment void unless for public welfare support, family support or union dues); Ohio Rev. Code Ann. § 1321.32 (Baldwin 1982) (assignment void unless for child or spousal support). Wage assignments are also prohibited in the states with the Uniform Consumer Credit Code. See U.C.C.C. $\$ 3.305$ (1974).

20. A number of jurisdictions prohibit some waivers of exemption based on the strong public interest in protecting debtors and their families. See, e.g., Industrial Loan \& Inv. Co. v. Superior Court, 189 Cal. 546, 209 P. 789 (1922) (prohibited in executory contracts); Mayhugh v. Coon, 460 Pa. 128, 137 \& n.6, 331 A.2d 452, 456 \& n.6 (1975) (citing cases).

21. Virtually all states impose some restrictions on the use of cognovit clauses. Some states bar the use of confessions of judgment altogether. Other states restrict their use in specified classes of transactions, such as retail installment sales contracts, but do not impose a general prohibition on their use. For an example of the former, see W. Va. Code $\S 46 A-2-117$ (1986). For an example of the latter, see Conn. Gen. Stat. Ann. $\S 42-88$ (West 1987) (confession of judgment void in retail installment contract or installment loan contract).

22. FTC Credit Practices Rule, 16 C.F.R. \$§ 444.1-.5 (1988).

23. The FTC rule defines household goods as "[c]lothing, furniture, appliances, one radio and one television, linens, china, crockery, kitchenware, and personal effects (including wedding rings) of the consumer and his or her dependents." Id. § 444.1(i).

24. See FTC Rule, supra note 4 , at 7743-45. There are a number of specific problems with the FTC rule as it is currently formulated. Most of the difficulties result from the overly broad prohibition of nonpurchase money security interests in household goods. The prohibition of security interests in household goods is not necessary to achieve the rule's objective. A valid, perfected security interest under article 9 of the U.C.C. gives the secured creditor priority rights vis-à-vis other creditors as well as default rights vis-à-vis the debtor. Thus, a creditor may be motivated to take security to ensure a priority position in any distribution of the debtor's assets irrespective of the right to foreclose against the collateral upon default. If the purpose of the FTC rule is solely to prohibit coercive remedies, then the rule should prohibit self-help repossession rather than ban security interests altogether.

25. See, e.g., supra notes 18-21.

26. There is substantial evidence that provisions for wage assignments, security interests in household goods, cognovit clauses and exemption waivers function as substi- 
2. The Current Debate Over Self-Enforcing Remedies. - The FTC rationale for regulation focused on the problem of lost value as a generic phenomenon. The FTC found that the prohibited remedies impose much greater injury on consumers than any benefits they provide for creditors. ${ }^{27}$ From this premise it was a simple step to conclude that the practices were "unfair" under a cost-benefit calculus. Further, the FTC concluded that regulation was justified because inherent information deficits prevented consumers from perceiving the potential for lost value and negotiating contracts without the suspect terms. ${ }^{28}$ Moreover, the inability of particular creditors to capture the benefits from innovation discouraged creditors in general from offering consumer contracts without the "harmful" clauses. Finally, the FTC concluded that the effects of prohibition on either the cost or supply of credit were likely to be insubstantial since the prohibited practices did not offer meaningful benefits to creditors in the first place. ${ }^{29}$

Recently, William Whitford has developed the lost-value thesis as a criterion for discriminating among different remedial options. ${ }^{30}$ Whitford focuses on the case of a creditor holding a security interest in the debtor's household goods. There are several reasons to believe that the value of the goods to the debtor (Vd) will exceed the value of the goods to the creditor (Vc). The debtor may have invested human capital in learning the particular characteristics of these goods, enabling her to exploit their use more fully. Furthermore, the debtor may

tutes for one another. For example, in California, where repossession and resale were regulated, wage assignments were prevalent. FTC Rule, supra note 4, at 7757 . In New York, where confession of judgment was regulated, waivers of exemption were widely used ( $75 \%$ of the cash loan contracts), id. at $7769 \mathrm{n} .10$, as were wage assignments $(68 \%$ of the small loan contracts), id. at 7757. Of those self-enforcing terms prohibited by the FTC rule, the most prevalent were security interests in household goods. Results of a survey of some 10,000 consumer accounts revealed that $76 \%$ of the precomputed loan contracts contained clauses authorizing household-goods security interests. Id. at 7762 n.12.

27. See, e.g., id. at 7767 ("Although the capacity to disrupt the home of a consumer and his or her family has some value to a creditor, the practice elicits minimal benefits in return for substantial injury.").

28. See id. at 7762-65.

29. See id. at 7745-47. The FTC based its judgment that the costs of prohibition were likely to be negligible on several grounds. First, it gathered statistics on the effects of selective regulation of self-enforcing remedies in states that already had enacted restrictions comparable to the proposed rule. This data indicated that interest rates would be unlikely to rise if any one of the family of self-enforcing terms was prohibited. Id. at 7780-81. Unfortunately, the FTC did not consider the possibility that these remedies may be substitutes, which appears to be the case, see supra note 26 . Since no state had prohibited all of the remedies banned by the proposed rule, the conclusions drawn from this data are problematic. The FTC, however, did commission several econometric studies of the likely effects of the proposed rule. The most sensitive of these studies suggested that the rule would cause an increase in the cost of credit of approximately $0.2 \%$. FTC Rule, supra note 4 , at $7779-80$.

30. See Whitford, The Appropriate Role of Security Interests, supra note 6, at 961-69. 
attach sentimental or idiosyncratic value to the goods. Finally, the repossession may impose psychic costs on the debtor, destroying the autonomy values attached to ownership of the goods.

Whitford then poses the following conundrum: if there is no prospect of collecting a deficiency, the parties should settle whenever Vd exceeds Vc. The debtor should pay the creditor some premium greater than Vc but less than Vd to forego its right to repossess. Nevertheless, Whitford claims, the evidence shows that creditors frequently do not settle. ${ }^{31}$ Rather, the parties reach an impasse and the creditor repossesses the goods, leading to a destruction of value. Furthermore, even if the creditor and debtor do settle, the outcome is coercive since it is reached only after both sides exercise strategic leverages. ${ }^{32}$ The creditor can threaten to destroy the premium value the debtor attaches to the goods, while the debtor can threaten to declare bankruptcy, convert the goods into exempt assets or otherwise engage in strategic delay. Whitford concludes that the problem lies in the use of self-help remedies, such as security interests in household goods. He argues for regulation that would channel the parties into remedial options such as wage garnishment for which potential lost value and its resulting coercion are unlikely. ${ }^{33}$

Alan Schwartz has challenged the lost-value thesis in an article arguing for the enforcement of security interests in consumer goods. ${ }^{34}$ Schwartz accepts the conceptual framework of the lost-value theorists and their focus on the postdefault relationship, but he challenges the assumption that lost value is a prevalent phenomenon. ${ }^{35}$ The conditions for a substantial destruction of value are unlikely to occur generally since a debtor's human capital investment in consumer goods is trivial, and the claim for psychic losses is entirely uncertain and speculative. Some debtors may have an idiosyncratic attachment to the goods, but this overvaluation will not be systematic. In any event, no debtor would knowingly grant the creditor a security interest in goods that he values more than the creditor does. In short, "repossession imposes trivial harms, no harms at all, or harms that cannot be shown to exceed the gains [to creditors], depending on how one considers the harm to have been inflicted." 36 Thus, Schwartz concludes that the lostvalue conundrum and the alleged coercion resulting from creditors'

31. Id. at 964 .

32. Id. at $964-65$.

33. Id. at $970-74$.

34. See Schwartz, supra note 8 .

35. Id. at $139-48$.

36. Id. at 147. It is important to note that Schwartz does not challenge the idea that debtors may hold assets to which they attach idiosyncratic or sentimental value. Rather, he argues that there is no reason to believe that debtors systematically would offer such assets as security. The cooperative model developed below argues, to the contrary, that there are good reasons for debtors systematically to offer such assets as security. Thus, the model shows that lost value is, at least in theory, a prevalent phenomenon. 
threats to repossess are largely cognitive illusions ${ }^{37}$ fueled by creditors' quite justifiable inclination to wholesale repossessed goods. ${ }^{38}$

3. The Limits of Conventional Analyses: The Zero-Sum Assumption. The current debate over lost value and its subsidiary issues (Do repossessing creditors systematically fail to maximize resales? Does self-help collection cause undesirable coercion?) remains unresolved largely because of a lingering uncertainty: are there any benign reasons why debtors would systematically grant creditors the opportunity to exercise postdefault leverage? The advocates of regulation argue that such leverage is both common and exploitative. ${ }^{39}$ They attribute the general use of such devices to market failures, cognitive errors and the unequal distribution of economic power between creditors and consumer debtors. Opponents of regulation, on the other hand, assert that the threat of lost value does not occur systematically and, when such leverage does exist, the resulting "coercion" is not normatively undesirable. ${ }^{40}$

Interestingly, even though current analyses reach different conclusions, they all would answer the question posed earlier in exactly the same way: no, there is no good reason for debtors to give lost-value leverage to creditors. ${ }^{41}$ The debate, then, proceeds from the same assumption. One side argues that the ad hoc evidence of lost value justi-

37. Id. at 139-48. Schwartz demonstrates that it would be irrational for secured creditors wishing to maximize profits to fail to maximize resale proceeds, unless each creditor acts in concert with others. Id. at 131-39. He then shows that creditor cartels are unlikely to exist. Id. The analysis is incomplete, however, because Schwartz assumes that creditors count only the monetary benefits of resale. See id. at 124 . His discussion of repossession as a signalling mechanism focuses solely on its effects on debtors. See id. at 151-52. But the signalling aspect of repossession also affects creditors. By reducing the default rate of other debtors, signalling through repossession allows creditors potentially to maximize profits without maximizing resale proceeds.

38. Schwartz justifies wholesaling on the ground that a dealer with experience in selling used goods can resell a good more cheaply than a creditor whose expertise is lending money. Id. at 130-32.

39. For example, Professor Whitford has observed that postdefault "leverage arises because the creditor has the capacity to take action of little direct benefit to itself but of great harm to the debtor. Our culture objects to gaining bargaining power solely by threatening to hurt another." Whitford, The Appropriate Role of Security Interests, supra note 6 , at 990 .

40. Schwartz, supra note 8, at 149-51 ("That creditors commonly so act should now seem less plausible .... [But] good reasons exist to make in terrorem repossessions, supposing them to occur. They may encourage repayment at least cost to debtors as a group ....").

41. See, e.g., id. at 140 ("These harms could not occur if debtors were perfectly informed of the consequences of granting security. If security imposed greater expected harms on debtors than it created expected gains for creditors, creditors could not purchase the consent of debtors to grant it."); Whitford, The Appropriate Role of Security Interests, supra note 6, at 982 ("[Regulation] can be seen as one more case in which the law steps in paternalistically to counteract a natural human tendency to favor immediate gratification-in this instance, more credit at lower prices-at the expense of protection from long-term risk."). 
fies regulation, while the other argues that the evidence is misleading and the problem does not exist.

This common starting point can be traced to a single-minded focus on the postdefault relationship between debtor and creditor. Viewed $e x$ post, creditor and debtor participate in what is essentially a zero-sum game. The outcome of a pure conflict situation inevitably results in a winner and a loser. Thus conceived, contract rights, including self-enforcing remedies, are part of the leverage available to creditors in seeking an advantageous resolution to the dispute. Consequently, the debate centers on whether the leverage is likely to be coercive (Is there a threat of destroyed value?) and the social and moral implications if it is coercive (Is coercion a bad thing?).

To be sure, the postdefault relationship between creditor and debtor is not strictly a zero-sum game. In the strict zero-sum game, there is no opportunity for cooperation or mutual advantage. Any gain for one player is offset by an equivalent loss for the other. Nevertheless, the zero-sum characterization of the postdefault relationship has useful heuristic value. It emphasizes the point that few opportunities for mutual advantage exist once default occurs. Even agreements to withhold imposing costs on each other are problematic since the exercise of such leverage is a crucial part of a winning strategy.

But the zero-sum conceptualization is fundamentally flawed irrespective of the possibilities of cooperative settlement. By focusing exclusively on the postdefault effects of creditor leverage, the current debate suffers from a curious myopia. Indeed, the myopia is not limited to the narrow question of lost-value leverage. A number of influential commentators have attempted to justify or explain, on various grounds, prohibitions on other terms in credit contracts, such as waivers of the debtor's right to seek a discharge in bankruptcy ${ }^{42}$ In each case, the analysis ignores the possibility that these provisions, which seem suspect after default, may play a valuable role in successfully regulating those credit relationships in which the debtor does not default. This is the peculiar problem of legal analysis. It concentrates on the transactions that break down rather than on those that succeed. I propose, therefore, to reconceptualize the debate by focusing on the ex ante relationship of the parties. From that perspective, the debtor-creditor relationship reappears as a cooperative bargaining opportunity-an interaction in which both parties are motivated to pursue mutual advantage, although each faces continuing temptations to defect from the common goal.

42. See, e.g., Jackson, The Fresh-Start Policy in Bankruptcy Law, 98 Harv. L. Rev. 1393, 1404-24 (1985) (justifying regulation as a corrective for impulsive behavior and systematic judgmental errors); Kronman, Paternalism and the Law of Contracts, 92 Yale L.J. 763, 784-86 (1983) (justifying regulation as a means of preserving personal integrity). For an analysis and further discussion of these arguments from the perspective suggested by this Article, see infra Part III. 


\section{B. The Consumer Credit Transaction as a Cooperative Bargaining Opportunity}

Consider the hypothesis that self-enforcing remedies are part of a complex regulatory scheme designed to enforce an agreement that is mutually advantageous to both parties. From this ex ante perspective, the consumer credit transaction resembles a cooperative bargaining opportunity-one in which the parties have incentives to form agreements in order to promote their mutual interests, but in which each faces the temptation thereafter to defect from the common objective.

The bargaining theory approach developed below will show that institutional impediments to legally enforceable contracting compel creditors and debtors to construct self-enforcing mechanisms to achieve their mutually desired objectives. The principal instruments available to the parties are contract terms providing for a reciprocal set of commitments designed to ensure that the objectives are achieved. Viewed in isolation or after the fact, these terms may seem harsh or difficult to rationalize with fully informed choice. But in the context of a cooperative bargaining situation, they appear as a useful regulatory mechanism designed to achieve a measure of mutual discipline and control. This mechanism has costs when the debtor defaults, but it is important to appreciate its value in improving the parties' capacity to achieve mutually desired and socially productive goals.

1. A Model of the Ex Ante Bargain.

a. Background Assumptions and Starting Points: The Enforcement Dilemma - Assume a world in which consumer credit transactions are negotiated individually. Creditors are firms that issue credit in a competitive environment characterized by easy entry and exit of capital. Debtors are solvent individuals who repay current obligations out of future income. All debtors have the right to a discharge in bankruptcy of any obligations they incur. Assume further that Creditor and Debtor enter into negotiations leading to a $\$ 10,000$ extension of credit that Debtor will repay in fixed installments. For purposes of the model, assume that both parties are rational actors, intent on maximizing their individual utility. Each party's objective is to minimize the costs of endogenous risks (those events within at least the partial control of one or the other) that will otherwise threaten successful performance of the credit contract. ${ }^{43}$

With these assumptions, the various factors that will influence the parties' agreement can be illustrated by a bargaining interaction in which each party has a pair of alternatives from which to choose. ${ }^{44}$ Each of the four possible combined choices yields a particular gain or

43. All of these very strong assumptions are explicitly relaxed infra in Part IIB, which tests the implications of the model in more realistic settings.

44. The cooperative bargaining model developed below builds on Thomas Schelling's pioneering work in applied game theory. See T. Schelling, The Strategy of Conflict 21-52 (1960); Schelling, An Essay on Bargaining, 46 Am. Econ. Rev. 281 (1956). 
loss for Creditor and a particular gain or loss for Debtor. Each party's choices will depend, in part, on the choice the other makes. Figure 1 represents the relationship between Creditor and Debtor in a two-dimensional graph, with Creditor's gains measured vertically and Debtor's horizontally and the values of the four combined choices shown by the points labeled $C D, C d, c D$ and $c d$.

\section{FIGURE 1}

\section{CREDITOR}

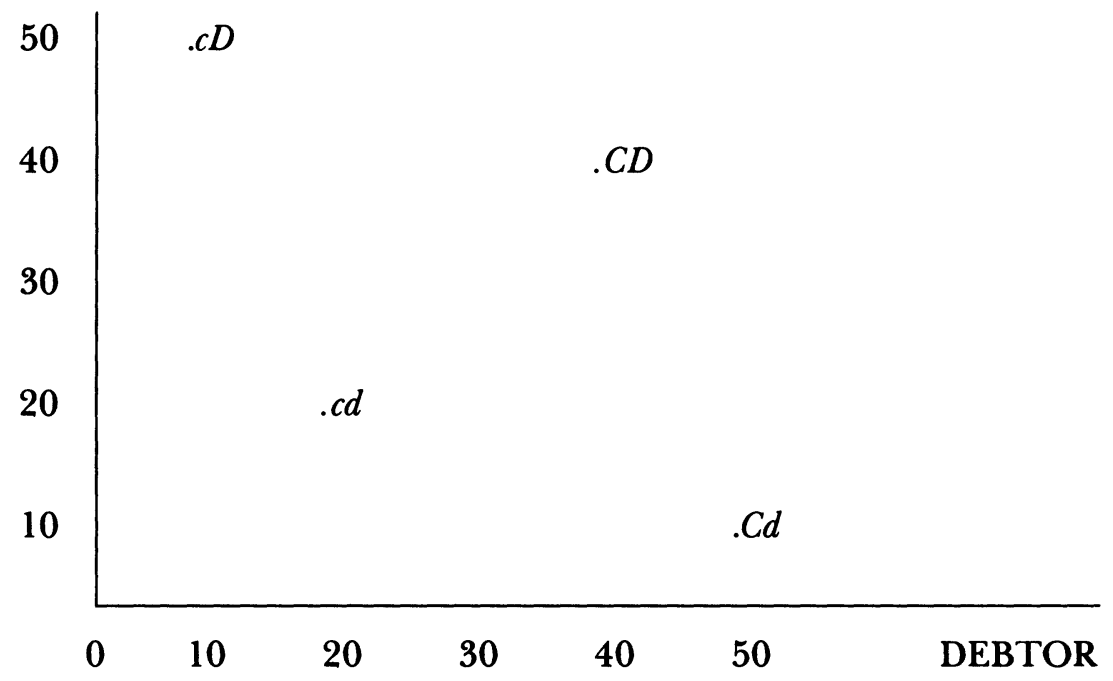

Creditor can choose either $C$ (lend the $\$ 10,000$ ) or $c$ (invest the resources elsewhere). Debtor faces a choice between $D$ (repay the loan in installments) and $d$ (retain her income and accumulate savings). The dilemma facing Creditor and Debtor can now be seen quite clearly. Solution $c d$ is a "minimax"- that is, it represents the outcome that minimizes the maximum risk of loss for both parties. ${ }^{45}$ Either can achieve $c d$ by itself, and neither can threaten the other with anything worse. Thus, it represents the "no contract" outcome, combining the returns to Creditor from its next best investment opportunity and the welfare position of Debtor if she accumulates the $\$ 10,000$ through individual savings.

Both parties would prefer $C D$, which represents the gains possible from the successful performance of an installment loan agreement. In order to reach $C D$, however, the parties must either trust each other or be able to make enforceable promises. This is because there is an in-

45. See T. Schelling, supra note 44 , at $48-49$; see also $R$. Luce \& $H$. Raiffa, Games and Decisions 275-309 (1957) (discussing the "minimax," as well as other well-known criteria for making decisions under conditions of uncertainty); Arrow, Alternative Approaches to the Theory of Choice in Risk-Taking Situations, 19 Econometrica 404 (1951) (surveying theories of choice in the face of uncertain consequences). 
herent first-mover disadvantage in the consumer credit transaction. As first mover, if Creditor chooses $C$ (to lend Debtor the $\$ 10,000$ ), Debtor has an incentive to choose $d$ (default, retain her income and accumulate savings instead of repaying the loan) in order to secure her maximum gain at $C d$. But solution $C d$ represents Creditor's maximum loss, motivating it to choose $c$ instead. ${ }^{46}$

In an ordinary contractual relationship, the legally enforceable promise resolves this dilemma. Creditor promises to lend Debtor $\$ 10,000$, and Debtor promises to repay the loan with interest in stated installments. Either party can rely on legal enforcement to ensure that they achieve the cooperative result $C D$. Unhappily, two factors in the consumer credit transaction impair the efficacy of the simple contract as a solution to the bargaining dilemma. First, if Debtor subsequently defaults, state law significantly restricts Creditor's ability to collect out of Debtor's current or future assets. ${ }^{47}$ Moreover, even this limited option to enforce the promise to repay is subject to Debtor's decision to seek a discharge in bankruptcy, an option that grants Debtor a fresh start unencumbered by Creditor's claim. ${ }^{48}$ Singly or in combination, these

46. In addition to the three possibilities discussed in the text, solution $c D$ remains a possible choice point as well. This option assumes that Creditor initially commits funds to Debtor, but subsequently recaptures the economic value of the loan (choice $c$ ) by inducing default even though Debtor is committed to repayment (choice $D$ ). This would be a sensible strategy for Creditor whenever changed circumstances (such as a shift in interest rates) make alternative investments (choice $c$ ) more attractive than the decision to commit the funds to this Debtor (choice $C$ ). This risk of creditor misbehavior is explored more fully below. See infra notes $65-68$ and accompanying text.

47. Debtors are entitled in all states to hold designated assets exempt from creditors' claims. Two examples of such protection are the exemptions of wage substitutessuch as pension funds and retirement income-and certain durable goods. See, e.g., Cal. Civ. Proc. Code $\S 704.010(a)$, (b) (West 1987) (exempting motor vehicles); id. $\S 704.100$ (a), (c) (life insurance policies); id. $\S 704.110$ (d) (proceeds from public retirement benefits); see generally T. Jackson, The Logic and Limits of Bankruptcy Law 264-72 (1986) (discussing attributes of exempt property). A number of states restrict the debtor's freedom to waive these exemptions. See supra note 20. In addition, the limitations on prejudgment attachment offer debtors the opportunity to use strategic delay in order to secure a more advantageous settlement. Postjudgment collection is similarly restricted. Wage garnishment is regulated by both state and federal law. Typically, a wage garnishment order in most states applies only to a single pay period, requiring a second garnishment proceeding for all but the smallest debts. See Whitford, The Appropriate Role of Security Interests, supra note 6, at 967-68. Federal law puts a ceiling on the available wage garnishment, equal to $25 \%$ of the individual's disposable weekly earnings or the amount by which those earnings exceed 30 times the federal hourly minimum wage, whichever is less. 15 U.S.C. $\$ 1673$ (a) (1982 \& Supp. IV 1986).

48. See 11 U.S.C. \& 727 (1982 \& Supp. IV 1986). From a historical perspective, discharge is a relatively recent addition to bankruptcy law. See Jackson, supra note 42 , at 1395 n.5. In order to obtain a discharge, the debtor must turn over all nonexempt assets to the bankruptcy trustee. 11 U.S.C. \$ 521(4) (1982). The exemptions granted an individual debtor in bankruptcy, however, are likely to be significantly greater than those afforded by state law. Under 11 U.S.C. $\$ 522$, the debtor may exempt either any property exempt under federal, state or local law or elect a laundry list of exemptions, including $\$ 7500$ in a homestead, $\$ 1200$ in an automobile, $\$ 4000$ in household goods, 
institutional constraints impair the parties' ability to rely on enforceable promises to achieve their objective.

The problem would not be severe if the only possible misbehavior of a solvent debtor were the bald-faced decision to default, accumulate exempt assets and declare bankruptcy. In that case, Creditor might be willing to trust that the punishing effects of such behavior on Debtor's reputation would effectively deter all but the most egregious cheaters. Creditor, however, is more acutely concerned with other, more subtle forms of misbehavior-actions that may ultimately impair Debtor's ability to repay even if she has a sincere desire to do so. ${ }^{49}$

b. Conflicts of Interest: A Typology of Debtor Misbehavior. - The bargaining dilemma of the parties can be seen more clearly by reviewing the variety of ways Debtor can cheat so as to leave Creditor with its maximum loss at $C d .^{50}$ The most obvious form of misbehavior is conversion. Debtor may consciously accept Creditor's money and then convert the income committed to repayment into exempt assets prior to seeking a bankruptcy discharge. Reputational constraints, as well as social norms of reciprocity, trust and promise keeping, regulate this behavior in many instances. ${ }^{51}$ Thus, Creditor may not regard the threat of conversion as sufficiently serious to cause it to force the no-contract option $c d$ (or to increase the interest rates and, in effect, move point $C D$ closer to the minimax solution).

Creditor, however, is also concerned with more subtle conflicts of

$\$ 500$ in family jewelry, $\$ 750$ in professional tools and $\$ 4000$ in unmatured life insurance. 11 U.S.C. $\S 522$ (d) (1982 \& Supp. IV 1986). Furthermore, notwithstanding any waiver of exemptions, the debtor may avoid any lien on such exempt property, including a nonpossessory, nonpurchase money security interest in household goods, jewelry or professional tools and implements. 11 U.S.C. \$ 522(f) (1982).

49. Even in a competitive market, where debtors have a strong desire to establish credibility so as to engage in future contractual relationships, reputation, good will and the benefits of repeat business do not completely deter the temptation to evade contractual responsibilities. See Klein \& Leffler, The Role of Market Forces in Assuring Contractual Performance, 89 J. Pol. Econ. 615, 618-25 (1981).

50. The following discussion builds on the analysis in Scott, A Relational Theory of Secured Financing, 86 Colum. L. Rev. 901, 919-22 (1986).

51. "[G]roup-generated norms, individual ethics, and other informal mechanisms play important roles in regulating contractual relationships." Scott, Conflict and Cooperation in Long-Term Contracts, 75 Calif. L. Rev. 2005, 2040 (1987); see id. at 2040-42. The pervasive social norm of reciprocity offers a peculiarly stable foundation for a strategy of conditional cooperation between contractors. See Gouldner, The Norm of Reciprocity: A Preliminary Statement, $25 \mathrm{Am}$. Soc. Rev. 161, 172-76 (1960) (reciprocity functions as a stabilizing force, cementing social relationships and discouraging exploitation); E. Walster, G. Walster \& E. Berscherd, Equity: Theory and Research 6-8, 15-16 (1978) (socially generated norms of equity discourage individuals from following their natural inclinations to maximize their own outcomes at others' expense). But norms of reciprocity and trust, standing alone, cannot guarantee a cooperative equilibrium. This is especially true when the prospect of future interactions between the parties is insufficient to discipline present temptations to defect from the cooperative norm. See Scott, supra, at 2024-30. 
interest. For instance, one widely recognized conflict is the danger that once credit is granted (Creditor chooses $C$ ), Debtor will increase the riskiness of her future income stream. ${ }^{52}$ She may decide, for instance, to invest the borrowed funds in high-risk investments. This behavior, which we might call risky business, permits Debtor to gamble with Creditor's funds. ${ }^{53}$ If the venture is successful, all the returns in excess of the debt payments accrue to Debtor. If the venture fails, Debtor, by declaring bankruptcy, imposes much of the loss on Creditor. ${ }^{54}$

A related conflict is the threat that Debtor may dilute Creditor's claim to Debtor's nonexempt assets. For instance, Debtor may overextend her capacity to repay by securing additional credit from other financers, who will then compete with the original creditor in any distribution of assets upon default. ${ }^{55}$ A promise not to incur further indebtedness does not solve the problem of overextension since the promise itself may be rendered unenforceable by subsequent bankruptcy.

Finally, Creditor may also be concerned about the vexing problem of shirking (or inadequate effort). The income to repay the loan is generated solely by Debtor's efforts. The promise to assign a portion of that future income to Creditor necessarily reduces, at least to some extent, Debtor's incentive vigorously to pursue income-generating activities. Instead, at least some of Debtor's efforts may be diverted to other activities for which all the returns are retained by Debtor. The shirking conflict means that debtors burdened with installment obligations will fail to exploit fully their income-generating opportunities even when further efforts would enhance the prospects of repayment in full at point $C D$ (the optimal result).

This last conflict of interest merely illustrates the general principle that a contracting party, obligated to extend efforts on behalf of herself and her partner, systematically will fail to exercise the effort necessary to maximize the mutual interests of both when a part of the returns from the contractual efforts must be repaid to the other in the form of a fixed royalty, commission or, as in this case, installment debt. ${ }^{56}$ Such arrangements skew the congruence of interests between Debtor and Creditor concerning the appropriate level of effort to be expended in reaching the cooperative goal of full performance at point $C D$.

52. See Jackson \& Kronman, Secured Financing and Priorities Among Creditors, 88 Yale L.J. 1143, 1149-50 (1979); Levmore, Monitors and Freeriders in Commercial and Corporate Settings, 92 Yale L.J. 49, 52-53 (1982).

53. The economist's designation of this conflict as "asset substitution" can be misleading. The conflict arises any time Debtor makes a financing or an investment decision that increases the variability of the expected returns. Frequently, Debtor's strategy will be to "put all her eggs in a single basket."

54. Scott, supra note 50 , at 919 .

55. The problem of claim dilution is especially troubling to Creditor when Debtor can use this additional debt to pursue high-risk, high-return financing options.

56. See Goetz \& Scott, Principles of Relational Contracts, 67 Va. L. Rev. 1089, 1112-26 (1981). 
How can these conflicts be resolved without recourse to legally enforceable contracts? It is important to see that at this initial stage of the Debtor-Creditor interaction, both parties have an equal incentive to structure their relationship so as to control these future conflicts. If they are unable to do so, they inevitably will choose the no-contract point $c d$ and forfeit the mutual benefits that can be derived from the relationship.

c. The Debtor's Commitment. - The parties must find some forms or terms of agreement that either reduce the incentives to cheat or that impose enforceable penalties. The possibility of trust between Creditor and Debtor should not be dismissed, but neither can it be presupposed. Indeed, trust is often achieved by the continuity of the relationship between the parties. ${ }^{57}$ In the installment-loan context, however, the future casts an insufficient shadow over the present to discipline reliably the current behavior of the parties. ${ }^{58}$

The structure of the bargain can be changed, and the prospect of successful performance at $C D$ improved, if Debtor can signal effectively to Creditor that she will not default and choose $d$ if Creditor chooses $C$ (to grant the credit). She can accomplish this only by overcoming Creditor's fear of being disadvantaged as the first mover. Debtor's choice, quite simply, is to assume a commitment-that is, to make a promise to choose $D$ (full repayment) subject to a strong penalty in the event she should thereafter misbehave in any of the ways that will lead to default (and to the defecting outcome $C d$ ). The possibility of making a commitment allows Debtor to overcome some of the deficiencies in legal enforcement. Debtor assumes a commitment to repayment $(D)$ and Creditor chooses either $c$ (to invest elsewhere) or $C$ (to grant the credit and accept repayment). Thus, the no-contract minimax of $c d$ is avoided. 59

The efficacy of this decision depends entirely on Debtor's ability to

57. See T. Schelling, supra note 44 , at $134-35$. A number of studies establish the significance of a prior reputation for being trustworthy in influencing the outcome of strategic interaction games. Investigators have shown that credible promises (those made by parties historically known to keep their word) induce more cooperation than promises made by parties with no established reputation. See, e.g., Gahagan \& Tedeschi, Strategy and the Credibility of Promises in the Prisoner's Dilemma Game, 12 J. Conflict Resolution 224, 229-31 (1968).

58. A precomputed loan is a relatively discrete transaction, in which the parties will not face repeated opportunities to adjust cooperatively over time. In the absence of a relationship that will encourage cooperative patterns of interaction, Creditor must depend on Debtor's incentive to maintain a market reputation for reliability. Klein and Leffler have shown that, even in a competitive market, the desire to maintain a reputation for credibility will not be sufficient to deter the temptation to shirk on contractual responsibilities. See Klein \& Leffler, supra note 49, at 618-25. The logic is that Debtor can always borrow from new entrants in the credit market. Creditor, realizing this, cannot rely on Debtor's desire to maintain a good reputation as a sufficient enforcement bond.

59. See T. Schelling, supra note 44 , at $121-22$. 
commit herself credibly to enforce the commitment against herself. In this case, Debtor must find a way to commit herself not to exploit the available option of bankruptcy discharge in order to escape the repayment obligation. Under current law, her range of choices is somewhat constrained. One obvious possibility is simply to waive her right to discharge this debt. But such waivers, even if freely and intelligently made, are unenforceable. ${ }^{60}$ As an alternative, Debtor may choose to grant Creditor property rights in Debtor's nonexempt assets. A security interest in nonexempt assets, such as Debtor's automobile, will survive bankruptcy ${ }^{61}$ and provide Creditor the option of repossessing the collateral upon default.

The right to repossess the automobile is not an assurance that, if Debtor defaults, the asset will be sufficient to repay the debt. That may or may not be the case. Instead, the value of the commitment derives from the penalty that it imposes upon Debtor, not from the benefit that it offers Creditor. An effective commitment by Debtor includes any maneuver that will leave Debtor in the position for which the option of choosing to default $(d)$ is no longer realistic because it imposes more costs than any benefits Debtor could derive from cheating. A credible commitment thus requires Debtor to assume a sufficiently severe penalty so that in all cases she would prefer to carry out her promise to pay in full (to choose $D$ ).

Thus conceived, granting Creditor the right of repossession allows Debtor to offer an economic hostage that accomplishes two critical functions. First, it signals to Creditor that Debtor is not one of those likely to defect by engaging in any of the types of misbehavior that would lead to $C d{ }^{62}$ In addition, the hostage serves a crucial bonding function. It ensures that Debtor's resolve to follow those steps neces-

60. See 11 U.S.C. § 524(a)(2) (1982 \& Supp. IV 1986) (“A discharge . . operates as an injunction against the commencement or continuation of an action, . . . or an act, to collect . . . any such debt . . . whether or not discharge of such debt is waived . ...").

61. See id. § 522 .

62. See Rea, Arm-Breaking, Consumer Credit and Personal Bankruptcy, 22 Econ. Inquiry 188, 196-97 (1984). Signalling theory, standing alone, does not fully justify the use of self-enforcing remedies. There is substantial question whether, in equilibrium, such signalling will, in fact, produce better matches between creditors and debtors. If there is too much signalling in equilibrium (because the signal is insufficiently informative), the social cost of using coercive remedies for these purposes may outweigh any informational advantages. See Schwartz, Security Interests and Bankruptcy Priorities: A Review of Current Theories, $10 \mathrm{~J}$. Legal Stud. 1, 14-21 (1981). Under these circumstances, debtors as a group would be better off if the signalling device were banned. The model proposed in this Article avoids this problem by linking the signal to debtors' precontract incentives. Thus, the signal works precisely because high-risk debtors can bind themselves to the results of the screening mechanism. Stephen Ross has developed a similar argument to explain the financing decisions of firms as signals to other participants in the market. Ross links the signal to the incentive system of the firm's managers. Thus, the firm is signalling that it has structured its managers' incentives so as to minimize the possibility that the managers can misbehave. See Ross, The Determination of Financial Structure: The Incentive-Signalling Approach, 8 Bell J. Econ. 23 (1977). 
sary to achieve full performance at $C D$ will continue unabated throughout the duration of the relationship. ${ }^{63}$

d. The Risk of Creditor Misbehavior. - Self-help repossession appears to offer the parties some hope of achieving the cooperative solution $C D$. Several drawbacks to the use of economic hostages, however, must be evaluated carefully. First, information barriers may prevent Debtor from revealing her value system so as to make the commitment credible. For example, the medieval king who sends a member of his entourage as a hostage to his enemy's court may be unable to alleviate the realistic fear that the king actually dislikes the hostage. One solution to the credibility problem is to offer as a hostage something of obvious value to anyone. Thus, the medieval monarch might choose as a hostage the most fearsome warrior in the realm. In the modern analogue, Debtor could offer a security interest in assets, such as the family jewelry, that have a ready market value equal to or greater than the outstanding debt. ${ }^{64}$

But this option, in turn, raises a further problem. If the hostage has independent value to Creditor, there is a heightened risk that Creditor will defect. Creditor may, for example, induce or fabricate a default after partial repayment, use the hostage to satisfy the old obligation and earn a further premium by investing the funds elsewhere. ${ }^{65}$ This option is reflected in Figure $1^{66}$ by the outcome $c D$, which represents Creditor's maximum gain and Debtor's maximum loss. Both parties profit, therefore, when Debtor's commitment to repay is credible, but Creditor is not enticed by the desirability of the hostage to the extent that it would rather keep the hostage than receive repayment.

In terms of the medieval monarch, this problem is best resolved by

63. The bonding function is independent of the signalling function. Even when Debtor's characteristics and reputation are well-known, agreeing to a self-enforcing remedy serves an important precommitment function in controlling ex post misbehavior. Thus, the signalling function of self-enforcing terms focuses on $e x$ ante contract negotiation, while the bonding function focuses on ex post contract enforcement. See Grossman \& Hart, Corporate Financial Structure and Managerial Incentives, in The Economics of Information and Uncertainty 107, 109-10 (J. McCall ed. 1982).

64. The original hostage imagery is Thomas Schelling's. See T. Schelling, supra note 44, at 135-36; see also Williamson, Credible Commitments: Using Hostages to Support Exchange, 73 Am. Econ. Rev. 519, 522-26 (1983) (formally developing a hostage model in the context of private ordering in intermediate product markets).

65. The risk of induced breach is a function of the "breacher-status" problem. See Goetz \& Scott, The Mitigation Principle: Toward a General Theory of Contractual Obligation, 69 Va. L. Rev. 967, 983 (1983). Any contract breacher, including a defaulting debtor, is liable for compensatory damages. But frequently overlooked is that a breacher will also lose his accrued interest in what may be very valuable return rights. Thus, there are advantages to a creditor inducing a default whenever interest rates rise or other market risks result in a debt contract favorable to the debtor.

66. See supra p. 742 . 
the king offering to his enemy his sickly son, the "puny prince."67 The value of the commitment of the puny prince lies in the king's love and affection for his son despite the prince's lack of physical strength. Yet the concomitant risk that the creditor monarch will provoke a default and make off with the hostage similarly is reduced since the puny prince is of little use as a warrior to anyone else. The puny prince theme suggests that for cases in which Debtor is offering assets as security, the ideal choices are family heirlooms, household goods, future human capital or indeed any other entitlements that have substantial idiosyncratic or sentimental value to Debtor. ${ }^{68}$ In short, the cooperative game reconceptualizes the lost-value differential, which seems so ominous once Debtor defaults, as the ideal economic hostage necessary to ensure the mutually beneficial outcome $C D$.

e. The Creditor's Commitment. - Upon reflection, however, there is a problem with the commitment of economic assets whose value to Debtor is largely idiosyncratic. Once Debtor defaults, the value of the hostage to Creditor may well be negligible. Debtor may now assume that Creditor will not exercise its legal right of repossession since repossession costs may well exceed any benefits in resale value. Yet, if the parties realize this possibility at the time of contracting, the entire cooperative sequence may unravel. In this circumstance, Creditor has an incentive to bind itself by committing to repossess upon default even though the cost may exceed the benefits. Unlike Debtor's commitment, the distinctive characteristic of Creditor's commitment is that Creditor has no intrinsic incentive to carry the act out either before the event or after. But it does have an incentive to bind itself to fulfill the pledge if it thinks the commitment is likely to succeed, since it is the making of the commitment to repossess, not its fulfillment, that gains the objective. ${ }^{69}$

Creditor, in committing to repossess upon default, must arrange its actions so as to demonstrate that it does have an incentive to fulfill the pledge if default occurs. But how can Creditor commit itself in advance to an action that it would prefer not to take if the event occurs? The difficulty, of course, arises from the fact that once default occurs, the incentive to respond by repossession or other means largely disappears. Thus, Creditor must demonstrate to Debtor how difficult it would be to undo the commitment after the fact. ${ }^{70}$ One way of making

67. See Scott, supra note 50 , at 930 .

68. These assets are largely exempt from creditors' claims in bankruptcy. See 11 U.S.C. § 522(d) (1982 \& Supp. IV 1986). Thus, self-enforcing terms are the only feasible way for Debtor to offer assets with idiosyncratic or premium value as a commitment to the cooperative objective.

69. See T. Schelling, supra note 44 , at $35-38$.

70. Given this situation, it is important for Creditor to tie its hands as much as possible. See id. at 40-41. Developing a reputation for carrying out the threat is important for Creditor because once Debtor defaults, and Creditor has to choose between repossession or not, the repossession move is suboptimal (repossession costs exceed resale costs by definition). Given that repossession is not Creditor's best move at the 
the threat credible is by contracting with a third party. For instance, Creditor may arrange for a debt collector or "repo man" to earn a fee for each repossession opportunity. ${ }^{71}$ Alternatively, Creditor can establish a reputation for credibility by precommitting to a rule that repossession will follow default regardless of the cost in individual cases. The credibility of the commitment is thus enhanced by Debtor's belief that Creditor is willing to maintain a reputation for consistency that will pay off ultimately in reducing the risk of default in subsequent transactions with other debtors.

The parties must be careful to define Creditor's commitment precisely, both in specifying exactly when the default triggers a response and the precise nature of the response. Creditor is motivated to develop a reputation for credibility at least cost to itself. Debtor, on the other hand, needs to recognize the threat so as to take precautions against default. Thus, the commitment to repossess should be clear and predictable and linked only to visible acts of misbehavior by Debtor. This does not present much of a problem in the Debtor-Creditor interaction when the only cause of default is assumed to be misbehavior by Debtor. But in real-world situations, a creditor must confront the possibility of default caused by purely exogenous factors, such as loss of employment. Because a repossession for reasons other than Debtor's misbehavior is costly to Creditor and does not enhance future performance by other debtors, Creditor would prefer to limit its threat to those defaults caused by Debtor's improvidence. ${ }^{72}$

Furthermore, it would be helpful if Creditor could divide the repossession threat into a sequence of discrete steps-such as telephone calls and letters-attaching to a series of ancillary symptoms of defection, each act escalating incrementally. The sequence of threatened

postdefault stage, the ex ante pledge to repossess may not be credible. Thus, the hostage will not perform its function: Debtor will have an incentive to misbehave because she believes that she can forestall repossession later on. In the context of the Debtor-Creditor interaction, therefore, it is important for Creditor to maintain the credibility of its commitment so that its entire collection experience will improve. While this analysis confirms that the commitment must be credible, it does not follow that Creditor must foreclose in every case. Rather, Creditor is motivated to set an optimal level of repossession, one that minimizes total enforcement costs. Optimal enforcement would require a frequency of repossession that minimizes the sum of the direct costs of enforcement (repossession) and the indirect costs (the increase in the risk of subsequent defaults attributable to reduced credibility).

71. In order for the use of a repo man to be a credible precommitment by Creditor, the repo man has to be in a position to determine, without the aid of Creditor, that Debtor has defaulted. Otherwise, Creditor can still cheat by failing to tell the repo man of the default. Thus, if Creditor simply refers defaults to the repo man, Creditor still retains discretion and the commitment may not be credible.

72. Creditor may not always be able to sort defaults attributable to endogenous risks from those caused by exogenous risks. Nevertheless, the motivation to limit the threat may explain the common practice of renegotiation and consolidation of delinquent accounts. See infra text pp. 751-52. 
acts attached to initial signals of misbehavior enables Creditor to demonstrate, by taking a few initial steps, that further transgressions will be followed by the ultimate step of repossession. ${ }^{73}$

The importance to Creditor of precommitting to an unambiguous rule of behavior is illustrated by a further problem: self-help remedies are ineffectual unless they can be communicated to the other party. In the case of the Debtor-Creditor interaction, the threat to repossess upon default can, of course, be communicated clearly to Debtor in the credit contract. But it is unlikely that a standard form contract term will also effectively communicate Creditor's resolve. This can be done best by developing a reputation as one who carries out the threatened act. The reputation is effective because it embodies evidence that a commitment to the threatened act has been made.

2. Postdefault Bargaining: The Effects of Self-Enforcing Remedies.

a. A Model of the Postdefault Bargain. - The nature of the bargaining environment changes dramatically when the debtor defaults on the repayment obligation. Assume in the Debtor-Creditor interaction that the agreement fails to deter the overconsumption of credit, and Debtor subsequently defaults on the payment obligation. Now the parties encounter a postdefault bargaining opportunity in which they both have an interest in undoing the reciprocal commitments. After all, the purpose of the threat is gone, and its deterrence value (at least for this transaction) is zero. This dilemma begins to look like a bargaining stalematea situation in which both parties are attached to incompatible positions. If there is a possibility of undoing the commitments (that is, foregoing repossession and leaving the pledged assets in Debtor's control), both have an interest in doing so.

The parties, however, may not have any common interest in how to retract the commitments. Creditor must maintain the credibility of the repossession threat in order to motivate cooperative behavior by other debtors. While maintaining credibility is important, it does not follow that Creditor must foreclose in every case. Rather, Creditor is motivated to adopt a variable strategy, choosing between repossession and settlement in particular contexts. This strategy enables Creditor to balance the direct costs of repossession against anticipated losses in credibility. Since repossession is costly to Creditor, Debtor is motivated to seek a compensatory concession in order to forego her right to declare bankruptcy. Because neither party is willing to sacrifice its postdefault position without compensation, it is entirely possible that the parties may be unable to collaborate in undoing the self-enforcement apparatus. Thus, the dynamics of the postdefault environment are much more like a zero-sum game than the cooperative opportunity that marked the initial negotiations. Strictly speaking, a zero-sum game is the limiting case of pure conflict, in which promises and commitments are not em-

73. See T. Schelling, supra note 44 , at $41-42$. 


\section{CREDITOR} \\ FIGURE 2}

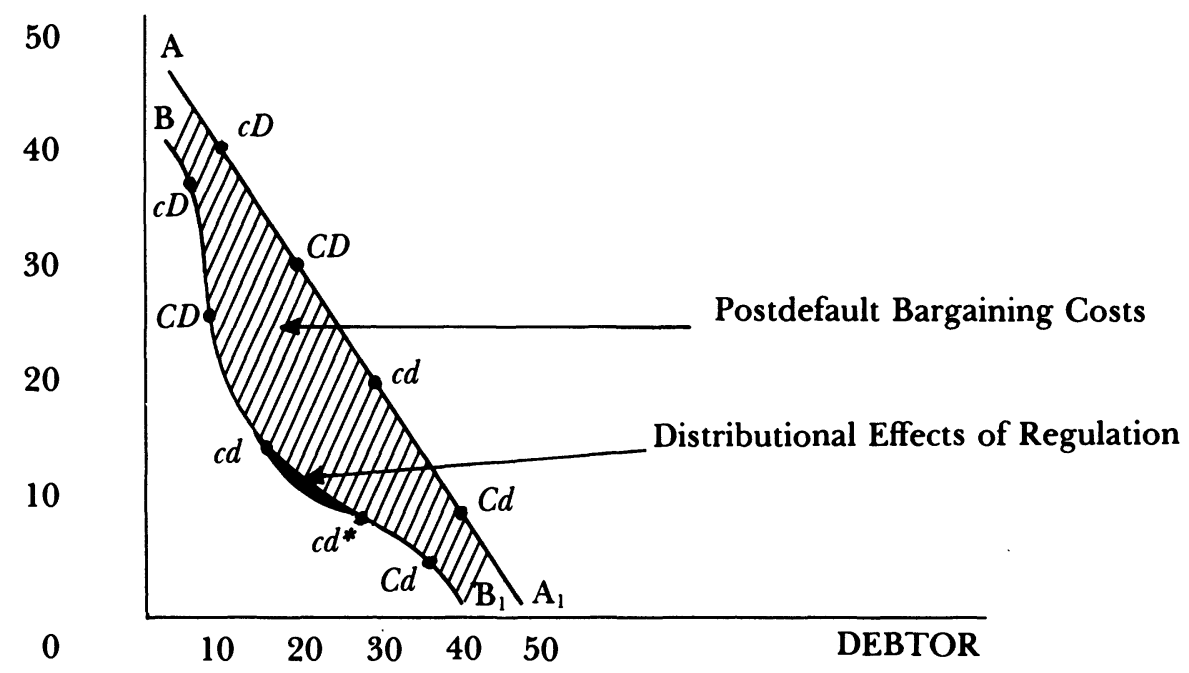

ployed at all. Instead, the rational strategies of the two players are to reveal as little about oneself to the other as possible.

In Figure 2, the postdefault relationship between Creditor and Debtor is depicted by two interactions (curves $A-A_{1}$ and B-B $B_{1}$ ), with Creditor's gains measured vertically and Debtor's horizontally. Dispute A represents a pure conflict situation (or zero-sum game) in which each party is aware of its own choices and has no ability to influence the other's choices. Each party has two options. Creditor can choose $C$ (settlement) or $c$ (repossession and resale). Similarly, Debtor can choose between $D$ (settlement) and $d$ (strategic delay or "stonewalling").

Under the conditions specified in Figure 2, dispute $\mathrm{A}$ has a minimax solution-one in which each party minimizes its maximum risk of loss at the impasse point $c d$ (coercive repossession). Repossession $(c)$ is the only rational strategy for Creditor. Creditor knows Debtor will elect to stonewall $(d)$ in all cases. Regardless of what Creditor decides to do, the option of stonewalling $(d)$ is better for Debtor than settlement $(D)$. Thus, Creditor's alternative choice of settlement $(C)$ will lead inevitably to $C d$ (the most costly solution for Creditor). Under these conditions, the parties will reach an impasse at $c d$ because neither can entice the other to agree to anything better. No collaboration is possible, and no commitments or promises can be made. ${ }^{74}$

74. The parties will not necessarily choose the minimax solution in all cases. Parties who are risk averse will always prefer a minimax strategy, but if the parties are risk neutral, they will prefer instead a strategy that maximizes their expected monetary returns. Maximizing expected utility may require deviation from the minimax point. In any case, 
Dispute B represents the same set of choices made under conditions of uncertainty. Each party is aware of the consequences of its own choices but uncertain of which option the other will choose. If the parties expend costs, represented by the shaded area in Figure 2, each one can discover what the other will do through bluffs, feints and other costly maneuvers. ${ }^{75}$ In dispute $B$, the parties also will reach an impasse at point $c d$. The principal difference between the two disputes is that the parties will reach the outcome in dispute B only after they expend costs in discovering the true state of affairs. If each party had known the truth about the other, they could have avoided the punishing maneuvers and agreed to share the resulting gains. But ignorance of the other's position does not change the ordering of the parties' choices. Nor, given the relationship among the various choices, will it alter the dominant resolution, which in this case is coercive repossession at $c d$.

The options may be arrayed quite differently in subsequent transactions. For example, fulfilling the repossession pledge will enhance Creditor's reputation for credibility and may make settlement a preferred choice thereafter. The problem of maintaining credibility always will have an important effect on the Creditor's choice between settlement $(C)$ and repossession $(c)$. Credibility further influences Creditor's motivations even when repossession and resale are the dominant choice. The repossession option is motivated, at least in part, by a desire to maintain a reputation for firmness. Thus, Creditor's normal incentives to maximize the proceeds of any resale are somewhat skewed. Uncollectible deficiencies are not necessarily a sunk cost for Creditor to the extent that they can be charged off as advertising Creditor's resolve in subsequent transactions. ${ }^{76}$ But, in any case, these uncertainties will affect only the magnitude of the gains or losses each party obtains from choosing its best response. Information asymmetries will not alter the structure of the postdefault bargain. And it is this structure, the relationship among the various choices, that will determine the outcome.

b. The Effects of Self-Enforcing Terms. - How, then, do self-enforcing remedies effect the outcome of these postdefault negotiations? Figure 2 shows that the bargaining costs of default are a product of each

the central thesis of the model remains unimpaired: if the parties cannot solve their information problems, they will be at disagreement points that are suboptimal.

75. The curve $B-B_{1}$ is represented as concave to the origin in order to reflect the intuition that the more parties attempt to learn about each other through costly maneuvering, the closer they approach coercive repossession at $c d$. Thus, if either party adopts an extreme position (stonewalling by Debtor or immediate repossession by Creditor) while the other is conciliatory, the total expenditure on bargaining costs will be reduced although the outcome will be disfavored by one party or the other.

76. This point partially supports the intuition of many observers that secured creditors do not systematically maximize the proceeds of a resale. The model presented here does not suggest that creditors systematically fail to maximize. But it does suggest that their resale decisions are subject to mixed motives. The normative implications of this analysis are discussed below. See infra text accompanying notes 142-43. 
party's uncertainty as to which option the other will choose. Thus, the choice among particular remedies, such as that between self-help repossession and postjudgment execution, should have no appreciable effect on the postdefault bargaining costs. As long as each party is unaware of the other's choices, each will engage in costly maneuvers designed to learn more about the position of the other. For instance, in the parlance of the consumer credit transaction, Creditor will expend substantial costs in discovering whether Debtor is a "can't pay" or a "won't pay." 77 Since this and similar facts are not easily communicated, each party needs to obtain evidence of the other's choices as revealed in her actions. Furthermore, in the Debtor-Creditor interaction, these facts are likely to be very difficult to discover. The determination of whether Debtor is a "can't pay," for example, will often turn on the ability of Creditor to coerce Debtor to convert funds from other debt obligations to satisfy Creditor's claim. Ultimately, of course, Creditor's ability to coerce a greater share of a fixed pool of assets can be trumped by Debtor's declaration of bankruptcy.

Thus, once Debtor defaults, the effects of self-enforcing remedies will be largely, if not exclusively, distributional. If Creditor is unable to bargain for the most effective remedial options, its power to force an advantageous resolution will be diminished since it must turn to more costly substitutes. Restricting Creditor's postdefault options also increases the cost of learning about the relative values of the choices available to Debtor. All things being equal, cost increases will reduce Creditor's power to claim a larger share of Debtor's assets. ${ }^{78}$

It is important to emphasize that the regulation of self-enforcing remedies will not eliminate the coercion inherent in postdefault bargaining. Each party continues to have the power as well as the incentive to threaten strategic moves in order to obtain valuable information

77. Empirical data, although incomplete, indicate that creditors regard the exercise of coercive remedies as the least efficient method of acquiring information concerning the debtor's options. The postdefault creditor usually proceeds through a series of extrajudicial "contacts," contractual rewrites, consolidations and extensions. As the delinquency continues, these contacts become more insistent and personalized, reflecting the creditor's motivation both to maintain the credibility of the ultimate threat of repossession, wage assignment or the like and to renegotiate delinquency in cases where default is involuntary. A 1971 survey by the Consumer Bankers Association indicated that prior to any repossession on delinquent accounts in automobile credit sales, there were an average of 3.6 extensions or rewrites, 10.3 delinquency notices, 12.2 telephone calls and 7.9 personal contacts. See Johnson, Denial of Self-Help Repossession: An Economic Analysis, 47 S. Cal. L. Rev. 82, 94 \& n.29 (1973) (citing Consumer Bankers Association, Repossession Survey for the Year 1971); see also 2 D. Caplovitz, Debtors in Default 1260 to 12-68 (1971) (discussing relationship between reasons for default and resumption of payments); Johnson, supra, at 85-88, 90-94 (cost-benefit analysis of actions taken prior to repossession and of repossession itself).

78. This result stems, in part, from the fact that strategic delay is one of Debtor's principal options. The longer it takes for Creditor to learn about Debtor's options, the greater Debtor's leverage from delay. 
about the other's choices. Even without self-enforcing remedies, Creditor will still use coercion (threatening to notify employers or making harassing telephone calls) in order to learn more about Debtor's options. And, of course, Debtor has an interest in using similar strategies to test Creditor's resolve. The coercion that is commonly observed once default occurs is a structural component of the relationship itself. Regulation will merely motivate the search for substitutes. The alternatives may be more costly or less effective, but they will inevitably be rooted in the same behaviors.

This point can be made more clearly by reconceptualizing dispute $\mathrm{B}$ in Figure 2 as a continuum of choices, with the minimax solution $c d$ falling along a fairly wide range of the curve $B-B_{1}$. The absence of a clear choice point is a more realistic approximation of the real-world interactions between the parties. A continuum of choices emphasizes the potential gains to each party from coercing adjustment within the range of solution $c d$. This distributional effect is illustrated in Figure 2 by point $c d^{*}$, which represents the minimax solution if Creditor must use a substitute method of coercion. ${ }^{79}$ Furthermore, visualizing the interactions as a continuum of choices suggests why the parties may often reach an impasse. The continuous range of choices deprives the parties of any "focal point" solution. No key characteristic of the relationship distinguishes it qualitatively from the surrounding alternatives. The lack of any focal point to the postdefault bargaining is one of the most important dynamic considerations in reducing the prospects for settlement. ${ }^{80}$

3. Summary. - The language of bargaining theory tends to cast the actions of the parties in starkly cool-headed and calculating terms. The cooperative bargaining model does not, however, require one to believe that debtors and creditors actually engage in negotiations that have this level of calculation. In real-world interactions, many of the bargaining moves on both sides will be reflexive, impulsive and intuitive. It is important, nevertheless, to appreciate the very strong motivations facing both Debtor and Creditor to devise a regulatory system to control conflicts of interest that otherwise threaten the viability of the agreement itself. Self-enforcing remedies function as reciprocal commitments that compensate for deficiencies in legal enforcement. This exchange of economic hostages creates mutual vulnerabilities. Debtor

79. Even with the use of repossession or wage assignments, Creditor's power to extort a larger settlement is limited by Debtor's option to discharge the debt in bankruptcy. Bankruptcy is costly to Debtor, however, since it involves both reputational losses as well as the loss of nonexempt assets that must be turned over to the bankruptcy trustee. Hence, the range $c d$ to $c d^{*}$ is fixed by the inherent structure of the relationship.

80. Thomas Schelling was the first to demonstrate the intrinsic magnetism of particular outcomes, especially those that enjoy prominence, uniqueness or some rationale that makes them qualitatively different from the continuum of possible alternatives. See Schelling, Bargaining, Communication, and Limited War, $1 \mathrm{~J}$. Conflict Resolution 19, 20-21 (1957). 
risks the loss of idiosyncratic value, while Creditor risks the loss of reputation (and consequent loss of revenue).

If Debtor defaults, the parties no longer face opportunities for mutual gains. The postdefault relationship is essentially a zero-sum game, in which any gains to one will be matched by offsetting losses to the other. Creditor is motivated by an optimizing strategy-choosing between repossession and renegotiation depending on the costs of each choice and the reasons for default. Debtor's choices, in turn, depend on whether it is optimal for Creditor to repossess or renegotiate in this instance. Thus, each party will use any available strategic leverage to reduce its uncertainty about the other's choices. Without any opportunity for mutually beneficial agreement, Creditor's access to coercive remedial options necessarily will have only a distributional effect. At this stage, restricting creditor remedies will advantage Debtor at the expense of Creditor.

\section{Testing the Model: The Dynamics of the Consumer Credit Relationship}

My purpose thus far in developing the cooperative bargaining model with some care has been to isolate certain structural elements that characterize and delimit the consumer credit transaction. As such, the question is not whether the model approximates reality, but whether it tells us something about reality that is useful to know. But even this more modest claim is not uncontroversial. In order to assess whether the model has utility as a heuristic device, two further questions must be resolved. First, to what extent does the available evidence of the nature of consumer credit transactions confirm the basic premises of the cooperative bargaining model? Second, to what extent is the model useful once its rather strong assumptions are explicitly relaxed?

\section{A. Evaluating the Data}

1. The Benign Function of Self-Enforcing Remedies. - The principal test for the cooperative bargaining conceptualization lies in its ability to predict patterns of interaction that are actually observed in consumer credit relationships. The evidence to test the validity of the hypothesis is sketchy at best. Nevertheless, some systematic efforts have been made to explore both the conditions underlying default and the parties' responses to these conditions. There are two major studies of the causes of consumer default, one by the National Commission on Consumer Finance (NCCF) ${ }^{81}$ and the other by sociologist David Caplovitz. ${ }^{82}$ Caplovitz surveyed a random population of consumer

81. V National Commission on Consumer Finance, Technical Studies (1973) [hereinafter NCCF].

82. D. Caplovitz, Consumers in Trouble: A Study of Debtors in Default (1974). 
debtors, whereas the NCCF relied on survey data from creditors.

Both studies suggest that consumer default derives from two principal sources: endogenous events, such as overextension, marital instability and irresponsibility, and exogenous events, such as loss of income or unemployment. Caplovitz found that although loss of income was the single most prevalent cause of default $(43 \%)$, the debtor's own improvidence or other endogenous risks triggered default a substantial amount of the time (36\%). ${ }^{83}$ Furthermore, debtors listed endogenous factors as the secondary reason for default 45 percent of the time. ${ }^{84}$ In adopting its credit practices rule, the FTC focused on the frequent involuntariness of the immediate causes of default and thus concluded that default was usually inevitable and unavoidable ${ }^{85}$ But, to the contrary, the data provide powerful indirect evidence of the existence of the sorts of conflicts that will motivate the parties to devise a scheme of self-enforcing remedies. Furthermore, the complicating factor of involuntary default helps to explain the evidence that creditors pursue a variable strategy in postdefault encounters, renegotiating some defaults and enforcing remedial options in others. ${ }^{86}$

The anecdotal evidence provided by creditors and their industry representatives strongly confirms the conception of self-enforcing remedies as a substitute for deficiencies in legal enforcement. Consider, for instance, the testimony of one witness who appeared in opposition to the proposed FTC rule. The testimony demonstrates both the psychological leverage that security provides to creditors and the importance of publicly demonstrating resolve in the face of refusals to pay.

$\mathrm{Q}$. "Did you ever have to junk it?" [The debtor's repossessed goods.]

A. "Yes!"

83. Id. at 53. Caplovitz categorized these events as voluntary overextension (13\%), involuntary overextension $(5 \%)$, marital instability $(6 \%)$, debtor's third parties $(8 \%)$ and debtor irresponsibility (4\%). Id. In the terms used in this paper, these defaults resulted (at least in part) from contingencies over which the debtors had some control. In turn, this suggests that the debtors did not take the creditors' interests fully into account when making postcredit financial decisions. Loss of income was listed as causing default in $43 \%$ of the cases, creditor misbehavior in $14 \%$ and miscellaneous misunderstandings in $7 \%$. Id.

The NCCF study found unemployment ranked as the most important cause of default by all classes of creditors. Overextension was found to be the second most important cause by banks and finance companies and the third most important cause by retailers. See NCCF, supra note 81 , at 9 .

84. D. Caplovitz, supra note 82 , at 53 .

85. FTC Rule, supra note 4 , at $7747-48$.

86. The FTC found that creditors with a blanket security interest in household goods repossessed in some cases and renegotiated in others. See id. at 7763. There may be two complementary explanations for this response. First, the cooperative model would predict that creditors would be motivated to renegotiate or excuse default ex post whenever its causes were involuntary. Second, even in cases of default caused by overextension, the model predicts that creditors would select an "optimal" level of enforcement that balanced repossession costs against lost credibility. 
Q. "You have to junk some of it?"

A. "Yes, and do you know why, are you interested?"

Q. "Certainly."

A. "Let me pose this as a hypothetical case-it is not hypothetical, it is actual. You have a number of families in one area who will be borrowing from you. If this fellow continues to go down the drain and continues to ignore his obligation and you try everything in the world to get him to pay and he is laughing at you and is saying - ."

Q. "You want to make an example of him for other people?"

A. "Not necessarily an example. But if you don't you are going to charge off the whole block." 87

Based on this testimony and other supporting evidence, the FTC found that despite the limited economic value of household goods, creditors rely on the threat of repossession to encourage debtors to continue to work toward repayment. ${ }^{88}$ Indeed, the predefault leverage created by idiosyncratic value was found to be a primary motivating factor underlying the common use of blanket security interests. Creditors reported that borrowers were much better disciplined if they pledged their household goods. ${ }^{89}$ The value of these self-enforcing devices is confirmed by evidence suggesting that alternative enforcement through judicial processes is inadequate. Creditors pursue a deficiency judgment only infrequently and on average recover no more than five to fifteen percent of the outstanding debt. ${ }^{90}$

The inference that self-enforcing terms reinforce a commitment to cooperate is supported by additional evidence. Creditors routinely decompose the threat of enforcement into a series of discrete steps, each action escalating incrementally. ${ }^{91}$ Furthermore, the data show that escalating threats to repossess are used by creditors to "compel" debtors to agree to refinance overdue obligations. The FTC found this psychological and economic leverage troubling because it was against the

87. Id. at 7763 n.36 (quoting Carl Waxman, North Carolina Consumer Finance Association). "The maintenance of credibility was offered as a reason for repossession by other witnesses." Id. (citing Michael Burns, Legal Aid Society of Minneapolis).

88. Id. at 7763.

89. See, e.g., id. at 7765 n.69 (citing Alan Susman, West Virginia State Senate, Owner of a Small Loan Company; George Prentiss, Citizens Budget Co.); see also id. at 7763 \& n.33 (quoting Helmut Schmidt, Vice-Chairman of Transamerica Financial Corporation) (" "There are two very, very important values to the furniture. One is the replacement value, the other is psychological, that enhances the sentimental value in heirlooms being provided .... ."). The psychological loss was mentioned "over and over again in the Commission proceedings." Id. at 7763 . The industry maintained that blanket security interests were valuable devices because " " $[t]$ his is the edge that makes the debtor pay." " Id. at 7765 \& n.68 (quoting James White, Counsel of State Credit Institutes).

90. Id. at 7783. 7764 .

91. A typical pattern of escalating threats is detailed in the FTC report. See id. at 
debtor's economic interest in some cases ${ }^{92}$ (although not necessarily inconsistent with the ex ante contractual objectives of both parties). Putting aside for the moment the understandable distaste for postdefault coercion, however, this evidence is entirely consistent with the predictions of the cooperative model. Moreover, the evidence suggests that the coercive postdefault behavior is not linked to the particular selfenforcing remedy, but to the creditor's motivation to discover the causes of delinquency and, if possible, to forestall default. ${ }^{93}$

The specialization of the market for personal loans provides further support for the claim that self-enforcing remedies encourage precautionary behavior by debtors. The data show significant variation in the remedial terms offered by particular creditors. Prior to the FTC rule, self-enforcing remedies were much more prevalent in the loan contracts offered by finance companies than in those offered by other creditors making consumer loans. ${ }^{94}$ Furthermore, the data rebut any inference that this specialization reflects a disproportionate concentration of low-income, high-risk consumers among the customers of finance companies. Rather, the evidence shows a substantial overlap in the borrower characteristics of personal loan customers of banks and finance companies. ${ }^{95}$ Thus, it is plausible to infer that most consumer debtors were able to choose between lower-cost credit providers who used self-enforcing remedies and higher-cost credit providers who did not.

In sum, the available data lend support to four basic structural claims of the cooperative model. First, conflicts of interest inherent in the "lend first, pay later" character of consumer credit will, unless restrained, threaten the successful performance of the contract. Second, self-enforcing creditor remedies function, at least in part, as a means of reducing anticipated conflicts and encouraging the debtor to consider both parties' interests when making subsequent financial decisions. Third, these self-enforcing terms are peculiarly useful because the alternative of legal enforcement is generally unavailable and, if pursued, will return only an insignificant portion of the remaining obligation. Fourth, postdefault coercion is largely a product of a sorting problem. Creditors are motivated to determine whether default is caused by exogenous factors (can't pay) or endogenous risks (won't pay). ${ }^{96}$

92. Id. at 7764-65.

93. See, e.g., id. at 7764-66; supra note 77.

94. "Results of a survey of over 10,000 current accounts of finance companies revealed clauses authorizing [household-goods] security interests in $76 \%$ of precomputed loan contracts." FTC Rule, supra note 4, at 7762 n.12.

95. See Boczar, Competition Between Banks and Finance Companies: A Cross Section Study of Personal Loan Debtors, 33 J. Fin. 245, 253-54 (1978).

96. If the debtor's improvidence causes the default, the creditor has an incentive to repossess in order to maintain its reputation for credibility. On the other hand, creditors prefer to renegotiate defaults caused by factors beyond the debtor's control. 
2. The Risk of Creditor Misbehavior. - The model suggests that the risk of creditor misbehavior is heightened whenever the debtor offers an economic hostage that is independently valuable to the creditor. ${ }^{97}$ Here the data offer supporting evidence as well. The claims of creditor fraud, induced breach and rush to repossession are almost exclusively linked to creditors with security interests in readily marketable consumer durables, such as automobiles. ${ }^{98}$ The FTC concluded that restricting deficiency judgments on automobile repossessions "would reduce the value of the collateral to creditors," and thus, regulation would raise credit costs. ${ }^{99}$ While this may be so, the claims of fraud and induced breach should be taken more seriously in these cases precisely because the economic hostage has independent value to the creditor. Furthermore, even here the creditor's motivations in reselling repossessed goods may not always lead to maximizing resale proceeds. To the extent that repossession despite large deficiencies advertises its resolve, the creditor can charge the deficiences off against subsequently successful transactions.

On the other hand, the data suggest that creditors repossess far less frequently in the case of blanket security interests in household goods. ${ }^{100}$ Indeed, in the case of blanket security interests, wage assignments and waivers of exempt assets, there is virtually no evidence of "excessive enforcement" or induced breach. Rather, as one might predict, the objections to these terms rest on the coercive effects of the leverage they provide in postdefault encounters. ${ }^{101}$ Once again, the FTC concluded from this that the right to repossess household goods or exempt assets, such as heirlooms, or to claim a portion of future earnings caused consumer injury with little corresponding benefits to creditors. ${ }^{102}$ But this evidence is entirely consistent with a cooperative bargaining approach. The value of the self-enforcing term is entirely prospective. If the focus is exclusively on the debtors who default, one would predict that the mutual incentives to undo the commitment

97. See supra notes $65-68$ and accompanying text.

98. See, e.g., Shuchman, supra note 17; White, supra note 17; Note, Business as Usual, supra note 17 , at $516-21$.

99. FTC Rule, supra note 4 , at 7784 .

100. Id. at 7763. This evidence is consistent with the prediction that creditors pursue an optimizing strategy in enforcing coercive remedies upon default. While repossession or other enforcement is seen as necessary to maintaining credibility, the costs of repossession deter creditors from a policy of universal enforcement. As the model predicts, creditors seek to convince debtors that repossession will be swift and sure, but then are reluctant to repossess when default occurs. One method of accomplishing this strategy is to renegotiate-and thus excuse default-in appropriate cases.

101. "Because of its low economic value, exempt property is rarely seized. Rather the common inclusion of waivers of exemption clauses suggests their primary use as in terrorem collection devices." Id. at 7769.

102. Id. at 7757-59 (wage assignments); id. at 7762-63 (household goods repossession); id. at 7769-70 (waivers of exemption). 
would reduce the rate of repossession and increase the incidence of coercive or in terrorem actions by creditors.

The single-minded focus on those consumers who default deprives us of the critical evidence that would illuminate more fully the consumer-debtor relationship. What we do not know, except by inference, is the social value of self-enforcing remedies in encouraging optimal precautionary behavior by debtors who pay. The evidence must, therefore, be regarded as inconclusive on the central claim that creditor remedies improve contractual performance in the overwhelming majority of cases in which no default occurs. Given that uncertainty, the prescriptive value of the model rests on its power once all assumptions are explicitly relaxed.

\section{B. Relaxing the Assumptions of the Model}

The bargaining model developed above was based on certain clarifying assumptions. In particular, it assumed that each player could evaluate rationally the choices available to her and make certain strategic moves designed to maximize her own interests. Furthermore, it assumed that controlling endogenous risks-in particular the risks of creditor and debtor misbehavior-was the only impediment to successful performance of the contract. Finally, it assumed that the parties could exchange perfectly calibrated economic hostages to overcome the deficits in legal enforcement of credit promises. A critical question, then, is whether the ex ante perspective is still useful when these assumptions are relaxed and the model is applied in a more realistic setting.

1. Rational Choice. - Bargaining theory is premised on an abstract model of rational choice. Highly idealized actors operate in a highly idealized setting, making highly idealized choices. Each actor seeks to maximize his expected utility. Nevertheless, in a bargaining model, rationality implies very little beyond a certain consistency of choice: if I prefer A to B and B to C, then I prefer A to C. ${ }^{103}$

Remember that the purpose of the model is not to describe either the actual behavior or the thought processes of the parties to consumer credit transactions. The conceptualization of the relationship in terms of carefully calibrated commitments and promises might seem to suggest that parties to this transaction engage in coolly rational strategic analysis both before and after default. This is not the case. Consumer debtors do not dicker for particular credit terms. On the other hand, available data suggest that most consumer debtors do have a choice between credit contracts with self-enforcing terms and contracts without such terms. ${ }^{104}$ This more realistic picture of consumer choice does

103. See H. Margolis, Selfishness, Altruism, and Rationality: A Theory of Social Choice 6-11 (1982).

104. See supra text accompanying notes 94-95. 
not undermine the value of the model so long as we assume that individual behavior is not random and that the individual is responsive to self-interest.

To be sure, the possibility that consumer debtors may be ignorant of their options or of creditors' likely responses, act impulsively or err systematically in making inductive inferences raises legitimate questions for policymakers. ${ }^{105}$ The strategies or heuristics used by individuals to make judgments about uncertain events are subject to bias and often deviate from the ideals of inference and probability assessment. ${ }^{106}$ Nonetheless, these cognitive heuristics are ingrained in individual behavior precisely because they are so useful. ${ }^{107}$ Thus, the evidence that individual judgment is flawed by cognitive errors is not inconsistent with the assumption that individual behavior is purposive. In turn, the evidence of ingrained problem-solving techniques, leading people to act purposefully, supports the inference that individual behavior may generally approximate the cooperative model even though individual judgments may be flawed by cognitive errors. ${ }^{108}$. In sum, this highly artificial scheme turns out to be a powerful aid to understanding what happens in the real world, where all of its very special assumptions are at best only crude oversimplifications.

2. Involuntary Default. - A more difficult problem concerns the simplifying assumption that the performance of credit contracts is only influenced by endogenous risks (the risks of misbehavior). Realistically, the parties must also consider the possibility of nonperformance owing to wholly exogenous factors such as involuntary loss of employment. It is one thing to exchange an economic hostage in order to protect oneself from weak will or one's own improvident future choices. This form of precommitment is a common choice-management technique. ${ }^{109}$ But it is quite another matter to enforce such a commitment when the default is caused by factors wholly beyond the debtor's control.

There are two possible responses to the problem of involuntary default. First, allocating exogenous risks of nonperformance to the party who bears the endogenous risks is a rational risk-distribution

105. The evidence of cognitive and volitional "error" is central to the normative claim that regulation of self-enforcing remedies is justified on efficiency or paternalistic grounds. See infra text accompanying notes 119-33 \& 159-75.

106. See infra note 124 and accompanying text.

107. See D. Kahneman, P. Slovic \& A. Tversky, Judgment Under Uncertainty: Heuristics and Biases 3-4 (1982).

108. See generally Mace \& Kratochwill, Self-Monitoring, in Handbook of Behavior Therapy in Education (1988) (reviewing clinical and experimental evidence of self-monitoring behavior in which individuals follow purposive, self-generated strategies of behavioral adjustment in order to realize desired goals).

109. See Scott, Error and Rationality in Individual Decisionmaking: An Essay on the Relationship Between Cognitive Illusions and the Management of Choices, $59 \mathrm{~S}$. Cal. L. Rev. 329, 342-47 (1986). 
strategy when it is difficult to distinguish legitimate claims of excuse from manufactured ones. Once an excuse category is recognized, the debtor has an incentive to claim excuse for all defaults, even those attributable to the debtor's improvidence. Since dispute resolution is both costly and imprecise, debtors may be able systematically to impose default costs on creditors. One method of resolving this problem, therefore, is to narrow (or eliminate) the circumstances in which excuse for nonperformance will be recognized. ${ }^{110}$ Alternatively, creditors can excuse some defaults in appropriate cases without announcing $e x$ ante that they will do so. ${ }^{111}$ In theory, debtors will be paid a premium in reduced interest rates in exchange for assuming these additional burdens. The gains that result from a more efficient risk-distribution scheme will be shared prospectively by debtors and creditors.

There is an alternative response to the problem of involuntary default. If consumer debtors are risk averse, they will benefit from an implied "force majeure" provision, ${ }^{112}$ a clause exempting debtors from responsibility for those exogenous risks they cannot control. Creditors, in turn, will agree to such a term, provided the interest rate can be adjusted to compensate for the prepaid default insurance. Assuming the grounds for excuse can be specified accurately, this contract will be optimal for both creditors and debtors so long as creditors can pool the risk.

The risk-bearing choices for exogenous risks will turn on which of these alternative scenarios is the more plausible empirically. But, in either case, the question of assigning the burden of events beyond either parties' control relates solely to excuses for breach of contract and not to the effects of particular creditor remedies. Even if self-enforcing terms were entirely prohibited, the debtor's default owing to circumstances beyond his control would not, under the current legal regime, give the debtor an excuse for nonpayment. Presumably, the creditor would remain free to pursue collection through the normal state-enforcement mechanisms. In short, however one reacts to the traditional reluctance of the common law of contracts to grant excuse for nonperformance, the issue is only tangentially relevant to the choice of self-enforcing terms.

3. Proportionality: Debtor Ignorance and Excessive Commitments. - A cooperative bargaining model assumes that Creditor and Debtor can design a pattern of reciprocal commitments that effectively constrains the

110. This approach best describes the reluctance of courts deciding commercial impracticability cases to grant excuse for nonperformance despite the apparent invitation to do so in the Uniform Commercial Code. See U.C.C. \$ 2-615(a) (1981). For a discussion of the relationship between judicial attitudes and the complexity of the issues in excuse cases, see A. Schwartz \& R. Scott, supra note 12, at 415-18, 427-28, 449-57.

111. This strategy seems to be widely used by creditors. See supra note 77 .

112. "Force majeure" excuses nonperformance attributable to any "circumstances independent of the will of man, and which it is not in his power to control." Lebeaupin v. Richard Crispin \& Co. [1920] 2 K.B. 714, 719; see U.C.C. § 2-615 (1981). 
debtor without unduly tempting the creditor. The metaphor of the puny prince is specifically intended to convey this key relation. ${ }^{113}$ In reality, however, the instruments available to the parties are inexact and potentially defective. Thus, one might fear either that debtors are unaware of coercive remedies and thus that the commitments are insufficient to encourage truly cooperative behavior, or that the commitments are excessive-too enticing for creditors or severe for debtors.

The possibility that debtors may be systematically unaware of either the presence or the effects of self-enforcing remedies seems quite remote. The precommitment argument does not depend on any details of the obligation being understood. It is enough if the debtor understands that she may lose her furniture or part of her wages if she defaults. Creditor actions against property or wages are salient facts, easily associated with default. ${ }^{114}$ Furthermore, unlike the systematic information asymmetries that plague warranty disclaimers and other terms in standard form contracts, the creditor has an interest in publicizing the consequences of default. Such announcements reinforce a reputation for credibility and promote the creditor's interest in developing a "brand name." 115

The problem of excessive commitments raises two separate concerns, each of which might form the basis for regulating particular terms in credit contracts. First, certain commitments simply may be too enticing for creditors, producing an unacceptably high risk of creditor misbehavior. The practice of pyramiding late charges provides a good illustration of such a potentially defective remedy. ${ }^{116}$ Pyramiding results from the assessment of multiple delinquent charges for a single late payment. Unless subsequent payments include the initial late charge, they, too, will be short and an additional delinquency charge will be assessed. The benign explanation for pyramiding is that the penalty reinforces a commitment to prompt payment of each installment. The threat of a continuing late charge is a means of decomposing the larger threat (repossession) into smaller steps attached to the ancillary actions that lead to default. Nevertheless, the risk of exploitation by creditors seems significantly higher here than with other selfenforcing terms. Pyramiding is based on an accounting method, not on a contract term. Thus, it is often unknown to consumers and could not

113. See supra text accompanying notes $67-68$.

114. It is likely, indeed inevitable, that individual debtors will be unaware of the presence and effects of self-enforcing terms. This possibility, however, merely supports an argument for reducing $e x$ ante information deficits, not for prohibiting the remedies altogether. See infra text accompanying notes 145-47.

115. The motivation of creditors to differentiate their "product" is revealed in the evidence that the market for installment credit is highly specialized. Small loan and commercial finance companies have used self-enforcing remedies extensively. On the other hand, such terms appear much less frequently in the credit contracts of commercial banks and thrift institutions. See FTC Rule, supra note 4, at 7762.

116. FTC Credit Practices Rule, 16 C.F.R. $\$ 444.4$ (1988), prohibits pyramiding. 
serve as a useful deterrent to late payments. On the other hand, the practice puts the debtor continuously in default and thus at risk of an induced breach even though all subsequent payments have been current.

The use of confession of judgment clauses may be similarly condemned. On its face, a confession of judgment simply transforms the state-enforcement system into a self-enforcing remedy. Since the remedy is only as good as the debtor's continuing solvency, it could operate as a "puny prince" hostage. But the opportunity to evade contractual risks such as warranty liability or interest rate shifts may be too tempting for creditors. The heightened risk of fraud or induced breach may thus require a prophylactic rule prohibiting the activity or the term altogether.

The risk of creditor misbehavior should not be overstated, however. Market forces will restrain many creditors from frivolous or erroneous enforcement against blameless debtors. The creditor's reputation is a valuable asset, one that contributes to the future success of the enterprise. The incentive to maintain credibility and good will reduces the risk of repossession whenever the debtor is not "at fault" in the ways described above.

The risk of excessively severe commitments is a further difficulty with the exchange of economic hostages in the real world. Consider the possibility that consumer debtors may systematically overcommit and agree to overly harsh sanctions upon default. The objection to extreme commitments-such as self-enslavement or forms of physical coercion-stems from the belief that less severe ways of bonding future promises are available and will be equally effective. Thus, a blanket prohibition of excessive commitments is simply a recognition that such bargains are almost always irrational.

In short, the possibility that debtors may overcommit justifies both the prohibition on extreme penalties and the tolerance of moderate ones. To be sure, the possibility of error in defining commitments and threats makes the real-world choices more difficult for policymakers. But the central theme remains unimpaired: self-enforcing remedies must be assessed in terms of their positive as well as their negative effects. At least in theory, both parties benefit from the inclusion of creditor remedies that have the potential to destroy value if the debtor should default. The remaining question is whether these potential benefits are overridden by legitimate concerns that justify current regulation even at the risk of sacrificing these gains.

\section{Normative Implications: A New Look at THE CASE For Regulation}

The preceding analysis argues for a fundamental reconceptualization of the nature and function of self-enforcing creditor remedies. This ex ante perspective recasts the several arguments for regulation. A 
prescriptive assessment of self-enforcing remedies begins with the norm of expanded choice. The expanded-choice postulate maintains that implied contract terms (including the standard remedies for breach of contract) are justifiable because they function to expand contractors' choices-providing standardized and widely suitable preformulated terms, thus eliminating the cost (and error) of negotiating every detail of the proposed arrangement. ${ }^{117}$ But this expanded-choice thesis implicitly presumes a neutral policy towards individualized agreements (including self-enforcing remedies). Atypical parties lose nothing since they remain unrestrained from designing customized provisions to replace the state-supplied terms. ${ }^{118}$ Prohibiting contract terms that reflect the apparent choices of the bargaining parties thus violates the norm and requires special justification.

There are three possible justifications for the prohibition of selfenforcing creditor remedies. First, market imperfections may cause contracting parties to neglect the interests of third parties or permit one party to exploit the other unfairly. Regulation corrects the market failure. Second, the regulation may be justified on paternalistic grounds. Here the law quite consciously overrules the judgment of the individual on the ground that she is incapable of perceiving her own best interests. Finally, the regulation may promote a socially desirable distribution of entitlements. In this case, the norm of expanded choice may be sacrificed in order to achieve distributional fairness.

The following discussion challenges each of the conventional arguments for prohibiting self-enforcing remedies. The analysis is complicated by the possibility that, notwithstanding the lost-value rhetoric, the current regulatory scheme can be explained and justified as a mechanism for restraining excessive consumption of credit. Thus conceived, the limitations on coercive collection may be only a proxy for a deliberate social policy of credit rationing. Nevertheless, at bottom, all attempts to justify current regulation rest on the evidence that individual debtors make systematic cognitive errors and are vulnerable to impulsive behavior. While these impairments are well-established, the compelling evidence that individuals use self-monitoring techniques and thus approach decision making strategically undermines the claims of aberrant judgment. The challenge, then, is to explore the failure of conventional theories and to discover why the intuition that regulation is a "good thing" persists. I conclude that the pressure for reform can be understood-if not fully justified-only by focusing on the strong perception that regulating coercive remedies promotes distributional

117. See Goetz \& Scott, supra note 65 , at $971-72$; Goetz \& Scott, supra note 56 , at 1089-90.

118. See Goetz \& Scott, The Limits of Expanded Choice: An Analysis of the Interactions Between Express and Implied Contract Terms, 73 Calif. L. Rev. 261, 264-89 (1985) (discussing the dynamics of the interaction between express and implied terms, and the extent to which the state implicitly regulates the formulation process). 
fairness-a perception that comes from individuals' aversion to bearing concentrated losses.

\section{A. Market-Failure Justifications}

1. Challenging Conventional Theories. - A contract term that results from an imperfection in the market or the bargaining process may not represent the true preferences of the parties. The notion is that regulation will correct the deficiency and induce people to reach agreements that correspond to the result they would have reached had the market operated properly. Three elements are required to justify regulation on the grounds of market failure: (l) a defect in the market; (2) a reason to believe that the defect generates contract terms that would not be chosen in a perfectly functioning market; and (3) a reason to believe that regulation will provide the necessary corrective.

a. Inadequate Information and Cognitive Error. - In the case of consumer credit transactions, several factors suggest that market forces will not produce optimal contract terms. The terms of credit contracts are not expressed in any standardized form, but instead are often formulated in arcane, technical language. Standardized terms would provide a uniform, and therefore intelligible, system of communication. A debtor who invested resources to understand fully the effects of a particular term could apply her knowledge to understand subsequent provisions cast in the same form. Thus, if creditors embodied remedial terms in a standard formulation, a debtor could compare more accurately the risks inherent in different combinations of terms. ${ }^{119}$ But individual creditors have insufficient incentive to provide clearer terms that are more easily comparable with available alternatives. Because an individual creditor cannot capture the benefits from educating consumers on the function of particular terms, each creditor has an insufficient motivation to encourage consumers to shop for different remedial arrangements. ${ }^{120}$ In short, high search costs, nonstandard formulations and insufficient incentives to provide clearer explanations of the effects of particular terms create information deficits that challenge the assumption of expanded choice.

Information deficits and high search costs, however, do not necessarily establish market failure. If the market is competitive, the pres-

119. See id. at 286-88; see also Schwartz \& Wilde, Imperfect Information in Markets for Contract Terms: The Examples of Warranties and Security Interests, $69 \mathrm{Va}$. $\mathrm{L}$. Rev. 1387, 1420-25 (1983) (exploring the effect of consumer comparison shopping on the competitive equilibrium of security-interest markets).

120. There are several reasons why market forces are inadequate to assure an optimal supply of clear, standardized contract terms. For example, " $[t]$ he limits of copyright law create an initial barrier to innovation by denying creditors substantial property rights in their formulations. An inherent free rider problem thus retards the production of innovative formulations .... [Furthermore, the] difficulty in coordinating a move to new contractual language constitutes another barrier to innovation." Goetz \& Scott, supra note 118 , at 292 (footnote omitted). 
ence of a sufficient number of "shoppers" should generate optimal terms even though the majority free rides on the efforts of those who shop. ${ }^{121}$ The conventional argument for regulation thus must rest on the premise that, in certain cases, systematic cognitive errors impair even the ability of the shoppers to bargain for the terms they prefer. Creditor remedies are seen as peculiarly susceptible to cognitive error because they are anchored to the prospect of default-a prospect that seems a remote risk at the time of contracting. The assumption that these terms are peculiarly susceptible to systematic errors of judgment supports the inference that the market cannot be trusted to generate an optimal contractual arrangement. By prohibiting the use of particularly worrisome contract terms, such as security interests in household goods, wage assignments and exemption waivers, the state may be able to ameliorate the more pernicious effects of cognitive error. ${ }^{122}$

At first glance, this seems a wholly plausible argument. Indeed, the FTC explicitly adopted it as the basis for the current credit practices rule. ${ }^{123}$ There is, after all, substantial social science evidence that consumers make systematic errors in their cognitive judgments and decisions. These errors are often attributable to heuristic principlesprinciples that are useful tools for simplifying complex judgments but that also can lead to severe biases. ${ }^{124}$ Of particular relevance to the case of creditor remedies are the powerful effects of the anchoring point-or how the choice is framed-in individuals' assessments of the gains and losses from any particular choice. ${ }^{125}$ Anchoring the coercive

121. See Schwartz \& Wilde, supra note 119, at 1402-16.

122. The arguments for regulation based on cognitive error are carefully summarized and analyzed in id. at 1425-50.

123. FTC Rule, supra note 4 , at 7747 ("the average consumer does not focus on elements of a transaction that are distant in time and probability").

124. For a comprehensive review of the literature, see D. Kahneman, P. Slovic \& A. Tversky, supra note 107; R. Nisbett \& L. Ross, Human Inference: Strategies and Shortcomings of Social Judgment 17-42 (1980); Abelson \& Levi, Decision Making and Decision Theory, in 1 The Handbook of Social Psychology 231, 233-34, 246-47 (3d ed. 1985); Edwards \& von Winterfeldt, Cognitive Illusions and Their Implications for the Law, 59 S. Cal. L. Rev. 225 (1986).

Experimental evidence indicates, for example, that individuals systematically ignore sample size and base rates in making probability assessments, an error designated as the "representativeness heuristic." In addition, the "availability heuristic" describes the tendency of individuals to be too strongly influenced in their inferences by the ease with which prior instances can be brought to mind. For a review of the experimental research that established these and related errors, see Tversky \& Kahneman, Judgment Under Uncertainty: Heuristics and Biases, 185 Science 1124 (1974).

125. According to the axioms of consistency and invariance, the preference order among options should not depend on the manner in which they are described. Using tests with experimental subjects, Daniel Kahneman and Amos Tversky explain the consistent failure of these axioms in terms of the dominance of the anchoring point in how individuals assess the gains or losses from any particular choice. See Kahneman \& Tversky, Choices, Values and Frames, 39 Am. Psychologist 341 (1984) [hereinafter Kahneman \& Tversky, Choices]; Tversky \& Kahneman, The Framing of Decisions and 
threat of self-enforcement to a remote risk may irredeemably impair the ability of consumers to evaluate the risk correctly. Moreover, the error will not be random. Individuals tend to overestimate the probability of conjunctive events, such as the events leading to successful repayment, and to underestimate the risk of disjunctive events, such as those causing default. ${ }^{126}$ As a result, consumers are not fully compensated for bearing the risk of coercive execution and (presumably) would prefer credit contracts without self-enforcing remedies.

This argument loses much of its force, however, when the question is reevaluated from an ex ante perspective. A bargaining approach focuses attention on the equally substantial evidence that individuals may voluntarily regulate or limit their choices in a variety of different ways. ${ }^{127}$ Thus, an inference of judgmental bias must be assessed together with the equally compelling evidence that individuals commonly employ a variety of self-monitoring techniques and thus approach decision making strategically. ${ }^{128}$ For instance, there are two possible expla-

the Psychology of Choice, 211 Science 453 (1981) [hereinafter Tversky \& Kahneman, Framing]. The relevance of framing variations for legal policy is discussed in Scott, supra note 109 , at $338-42$.

126. Tversky \& Kahneman, supra note 124 , at 1129 . These biases are explained as the product of anchoring. The overall probability of a conjunctive event is lower than the probability of each elementary event, whereas the overall probability of a disjunctive event is higher than the probability of each elementary event. Id. at 1128-30.

127. The theory of self-command or precommitment describes how the individual limits or modifies future behavior in order to ensure that a commitment to a present decision is not subsequently compromised. In essence, precommitment theory explores the motivations and devices by which a decision maker reinforces a choice made today by taking steps to prevent a contrary decision being made tomorrow. For a representative sampling of the economic literature, see Schelling, Ethics, Law and the Exercise of Self-Command, in Choices and Consequences 83 (1984); Thaler \& Shefrin, An Economic Theory of Self-Control, 89 J. Pol. Econ. 392 (1981); Thaler, Toward a Positive Theory of Consumer Choice, $1 \mathrm{~J}$. Econ. Behav. \& Organization 39 (1980). In addition, psychologists have done considerable research on the techniques people deliberately use to modify their future behavior. See, e.g., K. O'Leary \& G. Wilson, Behavior Therapy: Application and Outcome 470-73 (1975).

128. According to self-monitoring theory, an individual actively attempts to construct a pattern of behavior appropriate to a particular context or goal. For those individuals who monitor and regulate their behavioral choices, the impact of situational cues is likely to be considerable. Empirical evidence has provided documentation for these theoretical propositions. See Snyder, Cognitive, Behavioral, and Interpersonal Consequences of Self-Monitoring, in 5 Advances in the Study of Communication and Effect 181, 193-94 (1979); Snyder, Self-Monitoring Processes, in 12 Advances in Experimental Social Psychology 86, 121 (L. Berkowitz ed. 1979). Using information-processing concepts, Carver and Scheier have developed a complete theory of self-regulation that they call control theory. They suggest that an individual's focus of attention shifts back and forth between the environment and the self. They have experimental evidence that an increase in self-focus will cause conformity to situationally salient standards. See C. Carver \& M. Scheier, Attention and Self-Regulation: A Control Theory Approach to Human Behavior (1981); Carver \& Scheier, Control Theory: A Useful Conceptual Framework for Personality-Social, Clinical, and Heath Psychology, 92 Psychological Bull. 111 (1982). 
nations for consumers' apparent consent to self-enforcing creditor remedies. One is the biasing effects of framing. Many consumers may underestimate the costs of coercive action because the option is attached to a remote risk that is seen as the cost of obtaining a desired gain (the $\$ 10,000$ of credit). There is, however, another possible explanation for the revealed preferences of consumers for self-enforcing terms. Consumers may be accepting coercive remedies as a precommitment or self-command mechanism designed to discourage weak will and to control their own internal conflicts between short-term and long-term goals. By following such a rule-don't overextend your risky debt - the consumer can modify his future behavior in order to ensure that his commitment to a present decision to repay the obligation is not subsequently compromised. ${ }^{129}$

The reality of consumer choice in these settings cannot be established as a matter of pure theory, but the judgmental process of risk assessment appears to be inextricably linked to the equally important process of choice management. A legal policymaker thus must remain cautious about predicting the effects of legal intervention owing to cognitive errors. Even if policymakers see the biasing effects of framing as dominating, the best corrective is not the prohibition of self-enforcing remedies. The cooperative model argues instead for less intrusive regulatory alternatives because self-enforcing remedies will often be in consumers' self-interest. Alternatives such as disclosure and coolingoff periods reduce cognitive errors and also mitigate the information deficits that cause postdefault coercion. ${ }^{130}$

In sum, the assumption of chronic information deficits is not persuasive once the inference of cognitive error is integrated with a theory of strategic commitment and choice management. ${ }^{131}$ The conventional market-failure justification requires an inference of systematic exploitation of consumers that simply does not seem justified by the current evidence. The risk of systematic manipulation by simple framing illusions seems far less acute once it is recognized that consumers can and do routinely develop behavioral rules to regulate their future decision making. ${ }^{132}$ Moreover, the cooperative model demonstrates that legal

129. This argument builds on the discussion in Scott, supra note 109, at 337-42. Individuals are particularly likely to monitor their behavioral choices in environments that are novel, unfamiliar or able to motivate individuals to adopt a strategic orientation. See Snyder, On the Influence of Individuals on Situations, in Personality, Cognition and Social Interaction (1981); Snyder, Impression Management, in Social Psychology in the Seventies (L. Wrightsman ed. 1977).

130. See, e.g., FTC Cooling-Off Period for Door-to-Door Sales Rule, 16 C.F.R. $\$ 429.1$ (1988). For a discussion of these alternative forms of regulation, see infra notes 145-48 and accompanying text.

131. Cognitive error may have implications for paternalistic grounds for regulation. See infra notes 159-71 and accompanying text.

132. The behavioral rules that individuals use to govern their decision making are usually rational responses to situations. They might seem "irrational" only when one 
prohibitions may have unintended secondary effects. Regulation may well undermine the precommitment scheme that parties use to manage their credit choices. Indeed, the preceding analysis underscores the fallacy that state regulation of credit terms can ameliorate significantly the effects of cognitive errors. If consumers are susceptible to judgmental biases, then regulators are similarly imperiled. ${ }^{133}$

b. Externalities: Regulation as a Method of Credit Rationing. - William Whitford and others have argued that, notwithstanding the lost-value rhetoric, the regulation of self-enforcing remedies may have a broader objective: to restrain the overconsumption of consumer credit. ${ }^{134}$ There are several reasons to believe that unregulated credit transactions might result in a socially excessive consumption of credit. First, the presence of a pervasive system of social insurance programs means that debtors will not internalize fully the social costs of default. ${ }^{135} \mathrm{Un}$ employment benefits, food stamps and health care are all paid for as part of general taxes and available to defaulting debtors without regard to the riskiness of their credit activities. As with any insurance scheme, moral hazard causes the insured to underinvest in precautions to reduce the probability of claims against the insurance pool. ${ }^{136}$

Other externalities may skew the debtor's incentives. The effects of excessive debt may reduce social productivity as debtors shift to activities with a lower marginal social product or may blunt the entrepreneurial instincts of other potential debtors. ${ }^{137}$ Furthermore, the debtor may not consider fully the impact of default on dependents and other third parties. ${ }^{138}$ The claim that the parties do not internalize fully the social costs of default thus provides an alternative basis for state intervention. Limitations on self-enforcing remedies may simply be a crude but presumably effective method of credit rationing.

It is undeniable that substantial externalities impair the operation of consumer credit transactions. For example, the administrative costs

fails to take into account precommitment strategies and the transaction costs of deciding.

133. A seldom-appreciated point is that much of the decision theory literature is directed toward minimizing the judgmental biases of social science investigators and other neutral decision makers. See Abelson \& Levi, supra note 124, at 293-97.

134. See, e.g., Whitford, The Appropriate Role of Security Interests, supra note 6, at 998; Jackson, supra note 42 , at 1404-24.

135. See Jackson, supra note 42 , at 1401-04.

136. Rea, supra note 62 , at 191-92; Schelling, supra note 127, at 7 (“Any compensating program directed toward a condition over which people have any kind of control, even remote and probabilistic control, reduces the incentive to stay out of that condition and detracts from the urgency of getting out of it.").

137. This argument presumes that there are psychic costs to default that lead to excessive conservatism by third parties.

138. Interdependent utilities would seem to negate any inference that debtors fail to consider the effects of defaults on their dependents. Tom Jackson suggests, however, that the costs of communicating preferences even among family members will lead to underassessment by debtors. See Jackson, supra note 42, at 1419 . 
of a wage assignment may fall on the debtor's employer. Alternatively, the effects of repossession of personal property may be felt primarily by the debtor's friends, family or other third parties. Nevertheless, the externality claim suffers from two severe and related problems. First, even assuming the diagnosis to be correct, the cure does not fit the disease. Self-enforcing remedies cause debtors to internalize some of the costs of default. ${ }^{139}$ While regulation may reduce credit consumption at the margin, the curbs on coercive remedies will also encourage risk-seeking behavior by those who obtain installment credit and will exacerbate any third-party effects. ${ }^{140}$

Moreover, the regulation of self-enforcing remedies seems inadequate as a metering mechanism. Prohibiting self-enforcing remedies marginally reduces the supply of credit, and as a result, the absolute levels of credit defaults will fall. To that extent, regulating remedies does have a metering effect on overconsumption. But a cooperative bargaining perspective suggests that such regulation also increases the rate of default since debtors are less restrained from postcredit improvidence. In short, regulation designed to prevent overconsumption by prohibiting a mechanism for reducing the risk of overconsumption seems quite perverse. An excise tax on credit extension would appear to be a far more effective metering device if credit rationing is the goal.

2. The Case for Alternative Forms of Regulation.

a. The Problem of Creditor Misbehavior. - If the current regulation of coercive remedies is taken at face value, its purpose is to restrain undesirable and exploitative coercion in the collection process. On those terms, the regulation seems misfocused. Moreover, it ignores the structural imperatives that characterize the consumer credit transaction. If the commitment to self-enforcing remedies has significant predefault benefits for both parties, then substitute commitment mechanisms soon will be devised. These new commitments also will appear

139. One might argue, to the contrary, that coercive remedies will exacerbate the externality problem if the effect of enforcing the remedy (such as wage garnishment) is to cause debtors to quit their jobs. This might occur if the difference between the level of public welfare benefits and the allowable exemption from garnishment were so small that it was not worth it for debtors to work for the difference. This point, however, does not argue for prohibiting wage assignments altogether. Rather, it implies that wage exemptions must be set sufficiently above the relevant welfare entitlements so that a significant incentive to work remains.

140. Indeed, the argument can be rephrased in terms of insurance. The pervasive nature of social insurance and debt-forgiveness policies produces a moral hazard that self-enforcing remedies mitigate in much the same way that deductibles correct for moral hazard in the context of privately issued insurance. Thus, rather than being incompatible with social welfare norms, coercive remedies are an important complementary mechanism. See J. Elster, Ulysses and the Sirens: Studies in Rationality and Irrationality 85-86 (1979) ("It is crucial that there be some correlation between the extent to which individuals engage in risky activities and their contribution to social welfare funds: otherwise that refusal to bind themselves would be . . . an attempt to operate as free-riders."). 
coercive whenever a debtor defaults. And the substitute terms are likely to be less effective in regulating self-interested behavior by both parties.

Not only do current initiatives appear to increase the risk of debtor misbehavior (and thus increase the incidence of unsuccessful transactions), but the present scheme may have the pernicious effect of exacerbating the risk of creditor misbehavior. The distorting effects of the single-minded focus on postdefault coercion is vividly illustrated by the incoherence of the FTC's regulatory scheme. The FTC rule labels as equivalently injurious security interests in household goods and wage assignments while declining to prohibit purchase money security interests in consumer durables because the latter are seen as providing significant benefits to creditors. ${ }^{141}$

This distinction is perverse. The assignment of future human capital or a security interest in household goods is a paradigmatic illustration of a "puny prince" economic hostage. In both cases, the pledged assets are more valuable to the debtor than to the creditor. While these devices may or may not impose undesirable psychic costs, they have a benign function in disciplining the behavior of the creditor as well as the debtor. On the other hand, the purchase money security interest in consumer durables has independent market value to the creditor. The prime candidates for regulation are these types of self-enforcing terms that may present an unacceptable risk of creditor misbehavior. Some creditors may seize upon an excuse (perhaps a late payment) to induce default and to enforce the security interest by repossession, resale and deficiency suit.

Inducing default will be a sensible strategy for the creditor only if the gains from repossession or other enforcement exceed any reputational losses. Alan Schwartz has demonstrated that it is implausible to believe that creditors can systematically recover more than the outstanding debt without being obligated to return the surplus to the debtor. ${ }^{142}$ The model does cast some doubt, however, on the assumption that profit-maximizing creditors will necessarily maximize the proceeds of any resales. Clearly, creditors have incentives to maximize their net returns from enforcing security interests. But the resale motivation is partially skewed by the need to maintain a credible reputation for subsequent debtors. Large uncollectible deficiencies signal to other debtors the creditor's resolve to fulfill the repossession commitment regardless of the cost. The resulting advertising expense may be a profit-maximizing marginal cost that generates corresponding revenues through improved performance of other credit contracts. ${ }^{143}$

141. FTC Credit Practices Rule, 16 C.F.R. $\$ 444.2$ (1988); see FTC Rule, supra note 4 , at 7784 .

142. Schwartz, supra note 8 , at $132-39$.

143. Challenging the maximizing assumption does not, by itself, justify additional regulation of repossession sales. Under current law, the creditor, as the selling agent, is 
A plausible case for creditor misbehavior also arises when changed circumstances (such as a shift in interest rates) cause the creditor to regret the terms of the original credit transaction. Induced default allows the creditor to cover any losing market gamble and to continue to urge repayment for those cases in which the external market conditions remain favorable to the creditor. While evidence of market shifts that motivate creditors to misbehave might be generally available, it is unlikely that bad motives could be established in individual cases. Thus, the danger of unprovable fraud could provide the basis for a radical solution: the prohibition of commitments that may prove too seductive to creditors. ${ }^{144}$

The speculative nature of the misbehavior claims argues against the draconian step of regulating presumptive fraud. Many other factors, including competition and reputational constraints, bear on the question of systematic unprovable misbehavior. But, in any case, the irony is that the zeal to avoid "lost value" collection techniques may have led the FTC to ignore the potential for real exploitation.

b. Disclosure and Related Solutions to Predefault Error and Postdefault Coercion. - A bargaining theory approach does not imply that predefault judgmental errors and postdefault coercion are inappropriate subjects for regulation. Rather, the evidence that self-enforcing remedies may have benign as well as malignant effects argues for alternative regulatory devices. A cooling-off period prior to concluding the credit transaction offers individuals a valuable tool for correcting any judgmental errors in assessing the consequences of self-enforcing terms. Substantial research evidence indicates that access to such "tools" dramatically reduces the incidence of cognitive errors in individual decision making. ${ }^{145}$

Furthermore, the utility of self-enforcing terms depends on their clarity and predictability as signals of the parties' intentions. If these

required to dispose of the collateral in a commercially reasonable manner. U.C.C. $\$$ 9$504(3)$ (1981) (requiring that "every aspect of the disposition including the method, manner, time, place and terms must be commercially reasonable"). Presumably, this provision is violated if advertising costs are charged off against the defaulting debtor. Nevertheless, the difficulty in establishing the creditor's motivations in particular cases may argue for a more restrictive prophylactic rule.

144. The risk of creditor misbehavior that attends purchase money security interests in consumer durables raises a challenge to the cooperative model: if puny prince economic hostages are the ideal arrangement, why do debtors ever grant security interests in valuable assets? Clearly, purchase money security intersts serve traditional functions (an asset claim upon default and priority vis-á-vis other creditors) in addition to their possible utility as valuable precommitments. The prevalence of such arrangements suggests that their asset-based advantages dominate their inadequacies as economic hostages.

145. See Edwards \& von Winterfeldt, supra note 124 , at 267 . A possible solution to framing problems, for example, is to employ multiple framings, such as "(a) you have a $10 \%$ chance of defaulting on this obligation and (b) you have a $90 \%$ chance of successfully paying off this obligation." 
terms have been inadequately designed or tested, or are formulated in arcane language, they invite misunderstanding, disagreement and, ultimately, mutual conflict. As explained earlier, individual creditors have inadequate incentive to develop standardized and precisely calibrated self-enforcing remedies. ${ }^{146}$ One appropriate role for the state, therefore, is to specify a standard formulation for each provision that carries a legally unambiguous meaning. ${ }^{147}$ Standardization clarifies the choice between self-enforcing terms and postjudgment collection procedures. Improving the quality of the signal thus will enhance the credibility of the resulting commitment as well.

More vexing problems are evident in the postdefault maneuvers each party uses to discover the other's "reservation price." The model suggests that postdefault coercion is caused by each party's uncertainty about the choices preferred by the other and not by resort to self-enforcing remedies. This implies that undesirable coercion is better addressed by attempts to mitigate the information deficits faced by creditors and debtors. The problem the parties face once the debtor defaults is that information exchange, standing alone, is not likely to reduce bargaining costs. In this situation, "talk is cheap" and is not a substitute for action or strategic moves, even when the moves may be costly. While bluffs, feints and other maneuvers do not unambiguously reveal one's position (indeed, they may be deliberately deceptive), they nevertheless have an evidentiary quality that speech does not.

Arthur Leff has argued that the cost of postdefault coercion could be reduced by establishing a state-subsidized mediation service specializing in debtor-creditor problems. ${ }^{148}$ Mediation is essentially an extended settlement negotiation in which parties exchange confidential information to neutralize the risk of mischaracterization of the other's actions. Leff correctly saw that a disinterested referee could be an important ingredient in reducing the uncertainty of each party's estimates of the other's position. Unfortunately, daunting problems seem to frustrate any workable scheme to implement Leff's suggestion. It rarely will be in any individual creditor's interest to engage in voluntary collective mediation with other creditors. Each creditor has an incentive to pursue coercive collection individually in order to secure a larger share of the common pool of assets. Nevertheless, the information-based interventions suggested by Leff are worth exploring not only because they are less intrusive than absolute prohibitions, but also because they address the problem of coercion directly. This is espe-

146. See supra notes $119-20$ and accompanying text.

147. Although "[d]efinitional recognition does not change the optional character of these [express] terms," it does standardize the terms' meaning regardless of the context in which they are employed. Goetz \& Scott, supra note 118, at 282. Ideally, the parties should be able to pick and choose among a predetermined menu of such standardized remedial options in order to construct an optimal enforcement scheme.

148. Leff, supra note 6 , at $42-46$. 
cially true since the ex ante perspective casts considerable doubt on our ability to predict whether prohibition of credit terms is likely to ameliorate the problems caused by imperfect markets or to impose even more pernicious secondary costs.

\section{B. Paternalistic Justifications}

Under a criterion of consumer welfare, disclosure and other information-based solutions seem superior to prohibitions on self-enforcing remedies. Current regulation, however, may be justifiable on paternalistic grounds. Legal regulation is often motivated by paternalism. But paternalistic grounds for regulation rarely are acknowledged explicitly because often they are inconsistent with the norms of personal autonomy and expanded choice. As a result, some understandable confusion exists as to precisely which justifications are properly characterized as paternalistic. Duncan Kennedy has proposed a typology that provides a useful distinction between paternalistic, distributional and efficiency grounds for intervention. Kennedy defines paternalism as the overruling of the preferences of an affected group. The justification is paternalistic rather than distributive or allocative because the supposed beneficiaries do not agree that they are better off, and they would prefer to return to the prior regime were they free to do so. ${ }^{149}$

The key concept of overruling preferences suggests why regulations designed to correct cognitive biases or prevent difficult-to-detect forms of fraud are not necessarily paternalistic. The question is whether the affected parties, considering the issue free from the distorting effects of deception or judgmental bias, would agree that the regulation benefits them. To be strictly paternalistic, the regulation must be made for the benefit of the affected individuals whether they like it or not. Obvious examples of paternalistic regulation include the nonenforceability of contracts made by infants and incompetents, as well as prohibitions against self-enslavement. Notwithstanding the plasticity of the categorization, at least two regulatory traditions are strictly paternalistic.

1. Personal Integrity. - One form of paternalistic regulation is what Anthony Kronman identifies as "the idea of personal integrity."150 This idea embraces those prohibitions that preclude someone from trading away too much of his personal liberty. Examples include restrictions on self-enslavement ${ }^{151}$ or agreements not to divorce. ${ }^{152}$ Kronman attempts to ground the idea of personal integrity on the prin-

149. Kennedy, Distributive and Paternalist Motives in Contract and Tort Law, with Special Reference to Compulsory Terms and Unequal Bargaining Power, 41 Md. L. Rev. 563, 624-29 (1982).

150. Kronman, supra note 42 , at 765 ; see id. at $774-86$ (discussing personal integrity as a justification for paternalism).

151. See 18 U.S.C. $\S \S 1581-1588$ (1982).

152. See Kronman, supra note 42 , at $764 \&$ n.8. 
ciple of autonomy. But if personal integrity is defined as the liberty to use oneself in whichever way seems best, ${ }^{153}$ then the resulting regulation is inherently contradictory. One of the incidents of autonomy, after all, is the right to trade or exchange your entitlements whenever it is in your best interests to do so. ${ }^{154}$

The restraints against leveraging one's future personal liberty are better seen in terms of a communitarian norm. When individual integrity is compromised, the collective is diminished. Thus, the collective binds itself to forego those gains that can only be purchased by the sacrifice of an individual's self-respect. ${ }^{155}$

The problem with regulation based on the common good, however, is that the idea does not appear to have a limiting principle. Pushed to the extreme, a communitarian justification undermines the very notion of personal liberty that underlies individual entitlements. Kronman suggests that the limiting factor is whether the individual is able to depersonalize his commitment by substituting a monetary penalty or damages for the original commitment. ${ }^{156}$ The more impersonal the commitment, the less likely it is to threaten individual selfrespect. ${ }^{157}$

Thus conceived, the personal-integrity idea is a useful criterion for assessing the regulation of coercive remedies. It explains the universal reluctance to sanction physically coercive commitments (arm-twisting) that prove so effective in extralegal contexts. But self-enforcing remedies that impose only impersonal costs-such as those prohibited by the FTC rule-would not violate the personal-integrity norm. To be sure, the psychic costs of depriving an individual of a portion of current income or personal belongings may equally impair self-respect. Nevertheless, the distinction between commitments that are measured in money's worth and those that require transfer of the entitlement itself is well-entrenched in our legal system. At least on this basis, personal integrity is not sacrificed by self-enforcing creditor remedies. ${ }^{158}$

153. See id. at 775 .

154. See Schwartz, supra note 8 , at 154-56.

155. It is also possible to ground the idea of personal integrity in the concept of human fallibility (or poor judgment) discussed infra at text accompanying notes 159-75. Under this argument, individuals are not allowed to enslave themselves because there are alternative ways of earning money for food and shelter and of bonding future promises, and because the slavery penalty is so severe. A blanket prohibition might be seen as an acknowledgment that such bargains are almost always irrational. The same may be true for absolutely binding no-divorce obligations. This is particularly so given the enormous difficulty in ensuring that the other party to slavery or no-divorce agreements does not exploit the agreement. See E. Scott, Rational Decision-Making in Marriage and Divorce (1988) (unpublished manuscript on file at the Columbia Law Review).

156. See Kronman, supra note 42 , at $778-79$.

157. See id. at 780 .

158. A weaker form of the personal integrity idea would justify the prohibition of self-enforcing remedies as promoting minimum standards of decency in credit transactions. See Braucher, supra note 10, at 394, 428-29; Whitford, A Critique, supra note 6, 
2. Poor Judgment. - The idea of personal integrity does not explain prohibitions on the contracts of infants or incompetents or on the nonwaivability of bankruptcy discharge or the regulation of the riskiness of financial intermediaries. ${ }^{159}$ These restrictions are motivated by a second form of paternalism-the idea of human fallibility or poor judgment. The claim is simple: sometimes people need to be protected from themselves. ${ }^{160}$ Either certain people or all people under certain circumstances have insufficient capacities to know or choose the risks that (by some established criterion) they ought to prefer.

The poor-judgment claim differs from the simple cognitive illusion argument presented earlier. Here, the affected parties may not appreciate the restraint even after the biasing effects of the cognitive heuristic are removed. In the case of infants and incompetents, the classification is generic and rests on the assumption of immature judgment. ${ }^{161}$ Infants are inclined to recklessness and naiveté, and, in Kronman's words, they lack "moral imagination."162 Since the restraint is grounded in immaturity, it is temporal in character. Restraints of this sort are similar to the more familiar cooling-off periods found in other forms of contractual regulation. They merely postpone the opportunity to make a binding commitment in the future.

Whatever the legitimacy of the presumption of immature judgment, it is not relevant to our concerns. Specific prohibitions, such as the nonenforceability of waivers of bankruptcy discharge, involve re-

at 1112-14. A decency or humanist justification argues that a person's sense of self is irreparably impaired if personal possessions or cherished family heirlooms are taken (or given) away. Possessions give life meaning, and blanket security interests may impermissibly threaten these values. The decency justification for prohibition, however, suffers from two problems. First, it is hard to claim that self-enforcing remedies are more indecent than ordinary postjudgment execution. In both cases, a defaulting debtor may be deprived of property that she can ill afford to lose. If any aspect of consumer credit transactions is indecent, it is the freedom to enter into risky debt contracts that one may be unable to perform. More significantly, the argument that self-enforcing remedies are too harsh or oppressive assumes the very fact at issue-that these terms serve no beneficial functions. See, e.g., Braucher, supra note 10, at 428 (arguing that there is a "moral repugnance [to] threats that would have had only spite value if carried out"). If, to the contrary, self-help repossession serves important purposes in maintaining the parties' commitments, then the assumption that enforcement is purely gratuitous fails. In short, having empathy for debtors who default does not respond to the equally legitimate claims for empathy of those debtors who pay.

159. See, e.g., Clark, The Soundness of Financial Intermediaries, 86 Yale L.J. 1, 11-16 (1976).

160. Id.

161. See, e.g., Williamson v. Mathews, 379 So. 2d 1245, 1247-48 (Ala. 1980) (incompetence includes inability to reason and exercise judgment); Kiefer v. Fred Howe Motors, Inc., 39 Wis. 2d 20, 24, 158 N.W.2d 288, 290 (1968) (arguing that "the minor [is] immature in both mind and experience and that, therefore, he should be protected from his bad judgments"); R. Scott \& D. Leslie, Contract Law and Theory 341-66 (1988).

162. Kronman, supra note 42 , at $790-96$. 
straints that are both more severe and more focused. Thomas Jackson has developed a normative justification for the prohibition on discharge waivers based on a theory of overcommitment or aberrant judgments. ${ }^{163}$ Individuals are entirely forbidden from making certain commitments, Jackson argues, because in these specific instances their generally sound and reliable judgment systematically breaks down. ${ }^{164}$ Jackson's argument is a useful one to assess from the ex ante perspective of the cooperative model, since self-enforcing creditor remedies and discharge waivers are functionally similar terms. Presumably, their prohibition should rest on the same normative foundations.

Left to their own devices, the argument goes, many individuals will gamble with their futures, ignoring long-term preferences in order to indulge short-term desires. The literature on impulsive behavior provides at least some support for the idea of overcommitment. In a pioneering paper, R.H. Strotz demonstrated that, given plausible assumptions about the way future preferences are discounted, individuals whose preference ordering is constant nonetheless may make inconsistent choices over time. ${ }^{165}$ For example, an individual will choose smaller, earlier rewards despite an initial preference for larger, later ones. ${ }^{166}$

The paradox of rational decision makers acting on inconsistent preferences does not necessarily justify paternalistic regulation. The overcommitment justification requires policymakers to link volitional impairments with cognitive biases in order to isolate those specific instances when individuals are likely to suffer from weak will. ${ }^{167}$ Recent work by Daniel Kahneman and Amos Tversky provides at least some basis for such a determination. Kahneman and Tversky have developed a theory of judgment which posits that individuals evaluate choices in terms of incremental gains and losses from a given starting point or anchor. ${ }^{168}$ The biasing effects of the anchoring point may lead individ-

163. Jackson, supra note 42 , at $1405-18$.

164. Id. at 1415-18.

165. Strotz, Myopia and Inconsistency in Dynamic Utility Maximization, 23 Rev. Econ. Stud. 165, 166-71 (1956); see Hammond, Changing Tastes and Coherent Dynamic Choice, 43 Rev. Econ. Stud. 159, 161-63 (1976).

166. Strotz, supra note 165 , at $177-78$.

167. A volitional impairment occurs when an individual acts impulsively and inconsistently with her long-term preferences as she understands them. A cognitive bias occurs when an individual misperceives or misestimates her preferences. Thus, the argument in brief is that debtors are impulsive in general and likely to be especially impulsive in credit consumption decisions because their judgment is distorted by cognitive biases.

168. See Kahneman \& Tversky, Choices, supra note 125, at 344-45; Kahneman \& Tversky, Prospect Theory: An Analysis of Decision Under Risk, 47 Econometrica 263, 274 (1979); Tversky \& Kahneman, Framing, supra note 125, at 454. Based on a standard assumption of risk aversion, Kahneman and Tversky propose a theory of judgment with three key features: (1) individuals are risk averse in protecting gains; (2) individuals are risk seekers in avoiding losses (a sure loss is felt more heavily and, therefore, is more 
uals to overestimate the prospect of repayment and underestimate those events that might cause a default. ${ }^{169}$ Another of the axioms of their "prospect theory" is based on the demonstrated biases of individuals toward very low probability contingencies. ${ }^{170}$ Very low probabilities are either overweighted or neglected altogether, making such contingencies highly unstable in the decision-making calculus of the individual. Building on this research, Jackson argues that individuals would therefore prefer to bind themselves not to engage in impulsive commitments creating such a heightened risk of error. ${ }^{171}$ The regulation of discharge waivers, just like the regulation of self-enforcing remedies, thus represents a state-imposed commitment not to commit.

As Jackson freely concedes, this argument has difficulties. Chief among them is the mandatory character of the prohibition. Jackson's argument may well support an initial "off-the-rack" presumption against such contract terms. But it is more difficult to explain why (perhaps following a cooling-off period) specific individuals could not see it in their own best interests to make such commitments in particular instances. Jackson bolsters his theory, therefore, by arguing that mandatory regulation can be independently justified by the social interest in restraining overconsumption of credit. ${ }^{172}$

The poor-judgment claim overcomes some of the difficulties that undermine the externality argument for credit rationing. Here, the overconsumption criterion rests on a paternalistic assessment of human fallibility and not on the use of regulation as a market corrective. Thus, it avoids the inherent contradiction of correcting externalities by banning terms that actually internalize costs. Nevertheless, two key counterarguments are suggested by the cooperative model. First, the evidence that individuals approach decision making strategically should increase our confidence that they can use rational, self-generated rules to control against overcommitment and weak will. ${ }^{173}$ Moreover, the prevalence of precommitment techniques complicates the inferences that

distressing than a gamble between losing nothing or losing an even greater sum); and (3) losses loom larger than gains in human judgment when the prospects of either are equally probable. This "prospect theory" plays a pivotal role in current research on judgmental errors because it helps explain empirically observed behavior that violates the basic axioms of rational choice.

169. Tversky \& Kahneman, supra note 124 , at 1129 ; see supra notes $125-26$ and accompanying text.

170. Kahneman \& Tversky, Choices, supra note 125 , at 344-46.

171. Jackson, supra note 42, at 1415-16.

172. Id. at 1424. Recast in slightly different form, this claim is a variation of the externality argument outlined above. See supra text accompanying notes 134-40.

173. The use of economic hostages in installment loans not only bonds the debtor's promise vis-á-vis the creditor: it also bonds the promise vis-á-vis the debtor herself. Thus, it is a classic precommitment mechanism. Arguments based on irrationality or poor judgment typically fail to take account of this benefit because they tend to ignore the transaction costs of making choices generally. For a discussion of precommitment techniques, see Scott, supra note 109, at 345 . 
may properly be drawn from the experimental evidence of cognitive illusions. ${ }^{174}$ By banning a particular contract term, the state completely removes the arrangement from the range of choices available to similarly situated consumers. If expanded choice is the background norm, the policymaker should remove a transaction type from the market only if there is confidence that consumers' judgments are irredeemably impaired. While a simple cognitive error analysis may provide that confidence, the lessons of choice management argue against an uncritical reliance on such analysis. Since "irrational" choices may often be as plausibly explained by adherence to internal rules as by preference manipulation, it is unlikely that policymakers can accurately predict the cases of aberrant judgment. ${ }^{175}$

The social benefits of consumers' commitments offer a second reason to question the wisdom of blanket restraints. The paternalistic argument assumes that self-enforcing remedies or bankruptcy waivers only serve to indulge individuals' short-term impulses for overconsumption. Bargaining theory argues, to the contrary, that those devices are useful instruments to reinforce a commitment to socially beneficial long-term objectives. A bankruptcy discharge waiver commits the debtor's future human capital to the contractual objective. The commitment of human capital is credible since the asset is valuable to the consumer, but the risk of creditor misbehavior is remote since the asset is specific to the debtor and thus has no independent market value. Furthermore, a cooperative perspective suggests that both the debtor and the creditor believe the commitment is beneficial in reducing the risk of overconsumption. This perspective also moderates any inference of aberrant judgment. Neither the institutional orientation nor the individual loan officer, after all, is likely to be imperiled by impulsive behavior or other cognitive errors in this context.

In sum, regulating creditor remedies in order to meter the consumption of consumer credit is as problematic when the intervention is paternalistic as it is when the regulation is premised on market failures. In either case, the instrument for affecting the desired social policy seems unnecessarily crude and counterproductive. To solve the puzzle

174. See supra notes 127-33 and accompanying text. Recent work by Ward Edwards and Detlof von Winterfeldt has shown that cognitive errors are reduced if individuals are allowed to use "tools" or other intellectual aids to make probability assessments and inferences. Edwards \& von Winterfeldt, supra note 124, at 260.

175. The difficulty of drawing inferences directly from the cognitive error literature is compounded by the possibility that these various biases may in some cases offset one another. For example, in the case of default and repossession, one could argue that an availability bias moderates any anchoring effect. Repossession of household goods and wage assignments are fairly vivid and stark events; the risk of those events occurring may thus be overestimated to some extent, thereby correcting for the likely tendency to underestimate the risk of insolvency as an abstract matter. In effect, seemingly harsh repossession remedies serve to make the abstract risk of default more vivid and hence to counteract other risk assessment biases. 
of why this particular method of intervention has been selected, we need to turn finally to the distributional effects of regulation.

\section{The Distributive Justice Case for Regulation}

A redistributive justification for regulating self-enforcing terms rests on the premise that it is "fairer" or more just to change the current distribution of rights upon default in a way that helps one party or group at the expense of another. Since the regulation of creditor remedies clearly has distributive effects (at least for cases in which the debtor defaults), the distributional case for regulation is worth discussing in some detail.

Anthony Kronman has argued that terms found in contracts of adhesion, such as the consumer credit agreement, are properly subject to scrutiny on distributional grounds. ${ }^{176}$ If the imbalance of power reflected by the adhesion contract involves the distribution of control over important matters of social concern such as society's available housing stock, the terms are properly subject to regulation. ${ }^{177}$ Society cares about the fair distribution of certain essential rights and intervenes to achieve distributional fairness in such cases. Thus conceived, the prohibition of self-enforcing remedies shifts some of the control over the instruments of postdefault bargaining from one group (creditors) to another (debtors who default) in a way that furthers the widely shared goal of ensuring everyone a minimal freedom from psychic injury. To achieve this goal, the coercive remedies must be absolutely prohibited. Otherwise, debtors would be expected to waive their initial entitlement to noncoercive default, thereby restoring whatever distributional inequities existed at the start.

Kronman's argument leaves several key criteria unspecified. In the first place, he suggests that the distinction between power imbalances that are not the cause for social concern, such as the distribution of control over artwork, and those that require redistribution, such as power over the nation's housing stock, can be made by simple appeals to common moral intuitions. ${ }^{178}$ Furthermore, his criterion for inequitable distribution is the presence of standard form contracts. ${ }^{179}$ While standardization of contract terms is some indication of relative "power," it is a poor criterion for assessing the unfairness of a particular exchange.

At least some of the indeterminacy in Kronman's argument can be resolved by a more careful selection of a criterion for distributional fairness. A possible solution to the problem of how to measure distribu-

176. Kronman, supra note 42, at 770-74; see also Kronman, Contract Law and Distributive Justice, 89 Yale L.J. 472, 499-501 (1980) (discussing methods for achieving distributive goals through contract law).

177. Kronman, supra note 42 , at 771 .

178. Id.

179. Id. at 772 . 
tional fairness (putting aside for the moment the even more intractable problem of what we mean by fairness) is to adapt some of the instruments suggested by "superfairness" theory. ${ }^{180}$ Superfairness analysis is grounded in the games of fair division. Everyone is familiar with the concept of divide and choose: one person cuts the cake and the other then chooses. The utility of this process is that it achieves a fair distribution in terms of the preferences of the persons involved. The division may be objectively unequal; yet the process ensures that each party will receive a share that she prefers to the other's or at least that leaves her indifferent. ${ }^{181}$

The fair-division insight has been generalized into criteria of fairness that can be applied to any equitable distribution issue. A distribution is distributively fair if each class of participants prefers its own share to the share received by the other group-that is, if no one envies the other's distribution. ${ }^{182}$ An important qualification of superfairness theory is the distinction between the end-state fairness of a distribution and the incremental or marginal change in entitlements. A redistribution of entitlements often will be incrementally unfair in that the group whose holdings are reduced will envy the increment assigned to the other. ${ }^{183}$

Now consider how the superfairness criteria can be applied to the distribution of power to coerce a postdefault settlement. Assume, for instance, that the distributional question is posed in terms of control over the bargaining leverages that attend postdefault collection. The regulation of creditor remedies is distributionally fair if, even after the regulation of self-enforcing terms, each group would rather have the bargaining leverage assigned to it rather than the bundle of entitlements received by any others under the new distribution. ${ }^{184}$

180. Superfairness analysis is the phrase coined by William Baumol to refer to a literature that seeks to measure the equity or fairness of any particular distribution solely in terms of the preferences of the persons involved. For a representative sampling, see W. Baumol, Superfairness: Applications and Theory (1986); Pazner \& Schmeidler, Egalitarian-Equivalent Allocations: A New Concept of Economic Equity, 92 Q.J. Econ. 1671 (1978); Varian, Distributive Justice, Welfare Economics, and the Theory of Fairness, 4 Phil. \& Pub. Aff. 223 (1975); Varian, Equity, Envy and Efficiency, 9 J. Econ. Theory 63 (1974).

181. W. Baumol, supra note 180 , at $9-10$.

182. The superfairness criterion has intuitive appeal, but it is not uncontroversial. See, e.g., Holcombe, Applied Fairness Theory: Comment, 73 Am. Econ. Rev. 1153, 153-54 (1983). One of the major concerns is the primacy of envy (or the lack of it) as the calculus for equitable distribution. Thus, a distribution that benefits one group a great deal and another only a little may fail the incremental test of superfairness (although it may be superfair in end-state terms).

183. W. Baumol, supra note 180 , at 51-56.

184. This result is possible because the criterion is based on each party's own perception of the distribution. Creditors and debtors may have different preferences for exercising power and leverage, and thus, neither would envy the distribution assigned to the other. 
There are several reasons to reject this distributional account of the regulation of self-enforcing remedies. In the first place, fairness analysis is an incomplete normative theory. ${ }^{185}$ Using the absence of envy as a criterion for fairness does not aid in assessing the trade-off between distributional equity and the social or allocative benefits that these remedial options provide. ${ }^{186}$ Furthermore, the incidence of the regulatory change may be inconsistent with the distributional goal because it is impossible to predict a priori who will bear the cost of the regulation of credit terms. ${ }^{187}$ If supply is elastic and demand is not (along the relevant range), creditors will be able to raise the price of credit to reflect the distributional change, and thus the burden of the regulation will rest largely on those debtors who pay. The polar extreme is the case in which supply is inelastic and demand is elastic (again within the relevant range). Under these conditions, creditors will increase price only slightly or not at all, and the distribution will have the desired effect. The common assumption about capital markets is that barriers to entry and exit are low, implying that supply is elastic. ${ }^{188}$ Thus, it is likely that at least some of the burden of the regulation will fall on debtors who pay.

Perhaps more telling is the argument that those debtors who pay will be doubly burdened. Not only will they bear the distributional

185. A more complete theory of fairness would demand that the distribution be assessed as fair (under the chosen criterion) in terms of both incremental and end-state results. Furthermore, this distribution is likely to be only partially superfair-that is, no individual will envy the end-state distribution of the key consumption good held by the other, even though many might prefer the total bundle of entitlements held by the other. Finally, the superfairness criterion does not rule out all forms of envy. It only isolates the preferences for one's own consumption bundle. Thus, a superfair distribution does not imply that no one would prefer the total utility of any other. A more demanding criterion is the concept of superequality - an end-state distribution that yields each individual a utility level equal to or better than an equal division of all commodities. See W. Baumol, supra note 180, at 33-36. Given the current state of fairness analysis (in which the same criteria can yield different outcomes), the argument should be regarded as suggestive only.

186. Pazner and Schmeidler have proved that end-state distributional superfairness is not, in general, compatible with Pareto optimality. Thus, there are cases in which no outcome is both efficient and fair. See Pazner \& Schmeidler, supra note 180, at 674-75. Pazner and Schmeidler propose a criterion called "egalitarian equivalence" that purports to reconcile this conflict. An allocation is egalitarian equivalent if the distribution of utility could have been achieved by an equal division of all commodities. Id. at 672 .

Crawford has used this criterion to develop an auction procedure in which the chooser can select either one of the bundles offered by the divider (an auction) or the equal division bundle. This result yields a distribution that is both efficient and fair (in egalitarian-equivalent terms). See Crawford, A Procedure for Generating ParetoEfficient Egalitarian-Equivalent Allocations, 47 Econometrica 49, 51-52 (1979).

187. Scott, Constitutional Regulation of Provisional Creditor Remedies: The Cost of Procedural Due Process, 61 Va. L. Rev. 807, 836 (1975).

188. See Meckling, Financial Markets, Default, and Bankruptcy: The Role of the State, Law \& Contemp. Probs., Autumn 1977, at 13, 19-21, 23-24. 
costs in higher interest rates, ${ }^{189}$ but the regulation will deprive them of an effective instrument for self-command, one that would have reduced the expected risk of default. In short, even if end-state fairness is used as the criterion, it can still be argued that this distribution is not really superfair. Those debtors who anticipate being able to discipline their subsequent behavior to ensure repayment would, if they were aware of the economic reality of the matter, envy the distribution of control to those more likely to default. This is because the latter group benefits from an insurance policy largely subsidized by the former.

The puzzle, then, is how to account for the appeal of a distributional theory that disadvantages the many in order to benefit the few. One explanation is that the persistence of these regulatory initiatives depends more on the illusion of equity than on its reality. ${ }^{190}$ Consider the link between superfairness analysis, which focuses on an individual's perceptions of her share of any distribution, and the current research on economic illusions. For instance, the "endowment effect" follows from the human tendency to evaluate future choices in terms of gains and losses using the status quo as the anchoring point. ${ }^{191}$ This illusion leads individuals to weight out-of-pocket losses more heavily than foregone gains of equal expected value. ${ }^{192}$ All things being equal, goods that are included in the individual's current endowment will be more highly valued than those that have not been acquired. Systematic underevaluation of opportunity cost thus causes a bias in an individual's perceptions of his utility.

Furthermore, the phenomenon of loss aversion may also affect perceptions depending on the form in which the costs are imposed. ${ }^{193}$ For example, the evidence suggests that people prefer making multiple, small payments rather than a single, concentrated payment. ${ }^{194}$ This illusion explains voluntary excess income tax withholding as well as the evidence that lower income earners prefer a regressive sales tax to a

189. This problem is finessed in superfairness analysis by the concept of partial distributional fairness. A distribution is partially fair in terms of a defined subset of commodities (such as postdefault leverage) "if no individual is willing to exchange his holdings of those items for any other person's so that no one envies any other person's holdings of those items alone. W. Baumol, supra note 180, at 62-63.

190. This is not to say that the illusion of equity necessarily justifies the prohibition of terms that may well have positive benefits for debtors who do not default. Rather, the superfairness idea is a competing normative theory-one that willingly sacrifices the social benefits forecast by the cooperative model to achieve a distribution of entitlements that is perceived as "fairer."

191. This analysis builds on Thaler, Illusions and Mirages in Public Policy, 73 Pub. Interest 60, 64 (1973).

192. See supra note 124 .

193. The terminology is from Kahneman and Tversky. See Kahneman \& Tversky, Choices, supra note 125, at 344-46. The concept expresses the intuition that a loss of $\$ 100$ is more unpleasant than a gain of $\$ 100$ is attractive. This explains the observed reluctance of individuals to wager on a $50 / 50$ chance, such as a coin flip.

194. W. Baumol, supra note 180 , at 211-12. 
progressive income tax. ${ }^{195}$ The regulation of coercive creditor remedies may trigger both of these economic illusions. The benefits from coercive collection are both diffuse and expectational. The losses that result from postdefault collection are large and out-of-pocket. It should not be surprising, therefore, that the regulation of coercive remedies is commonly perceived as distributively fair.

The pervasiveness of these illusions is relevant to the very concept of fairness. Indeed, this connection suggests that the salient factor for legal policy is the effect of cognitive illusions on individuals' perceptions rather than their judgments. ${ }^{196}$ Assume that the costs of the distributional change are, in fact, divided unequally between debtors who default and those who do not, but that the debtors who do not default are under the illusion that they, too, have received the better share of the distribution. Under the criterion of superfairness, the distribution is equitable as long as one group does not envy the other group. On this view, what is significant is not the distribution the individual actually receives, but the pleasure he obtains from it. ${ }^{197}$

The preceding analysis suggests why policymakers often choose regulatory reforms that have uneven distributional effects. Concentrated costs are weighted more heavily by decision makers than are diffused costs precisely because the latter are not perceived as costs at all. Thus, to conclude, as I do, that the prohibition of self-enforcing remedies rests on a perception of fairness is not to dismiss the significance of that perception. The social benefits that are provided by access to credible commitments are undervalued. The social costs of those mechanisms when debtors default are magnified. It is this very illusion that is captured in the conception of "lost value."

\section{ConCLUSION}

This Article has argued for a reconceptualization of the regulation

195. Id. at 219-20.

196. This point develops an argument I have made elsewhere. See Scott, supra note 109, at 330-37. The vast literature on human error and cognitive illusion has been misunderstood by legal analysts. I contend that the focus on correcting errors of judgment is misplaced because the process of judgment involves several interrelated processes, including the method by which an individual manages her choices. Furthermore, linking the research to poor judgment inevitably leads to the problematic assumption that legal regulation can correct inherently fallible behavior. The connection to perceptions is more suggestive because it treats the cognitive illusions as a constraint and not a variable. Thus, the question is rephrased in terms of how the evidence of these illusions illuminates some basic legal institutions, including the notion of distributive fairness.

197. W. Baumol, supra note 180 , at 221 . It is important to remember that these illusions are ingrained in individual judgments and perceptions precisely because they are so useful in ameliorating the stresses of decision making. The error or illusion that this research illuminates is the deviation between empirically observed behavior and some theoretical conception of ideal rationality. Thus, knowledge often is incapable of dispelling the illusions. 
of self-enforcing remedies. A necessary first step is to clarify the objectives of regulatory reform. The stated reasons for prohibiting certain remedies are to protect defaulting debtors against coercive threats and lost-value executions. But a single-minded focus on postdefault enforcement distorts the analysis. A cooperative bargaining model of consumer credit suggests, to the contrary, that these self-enforcing terms also have a beneficial function in reinforcing the parties' commitment to the contractual objective.

Thus conceived, the current scheme of regulation is difficult to justify on either economic or paternalistic grounds. The assumption of market failure cannot be sustained once the considerable ex ante benefits of self-enforcing terms are acknowledged. Indeed, the analysis shows that the risk of creditor exploitation is more acute when the creditor takes a security interest in consumer durables (currently unregulated) than in cases in which the security interest is taken in household goods or wage assignments (currently prohibited). Furthermore, the undesirable coercion associated with postdefault enforcement is better reduced by disclosure and other information-based forms of regulation. The idea of personal integrity provides an alternative basis for prohibiting certain kinds of agreements that impair personal freedom and self-respect, but the debtor's ability to depersonalize the commitment with a monetary payment argues against such paternalistic interventions here.

Perhaps the lost-value rhetoric masks a different objective: the social interest in restraining the overconsumption of credit. On these terms, regulating self-enforcing remedies may serve a credit-rationing function, increasing the cost and thus reducing the supply of credit. The case for overconsumption rests on either of two bases. Pervasive social insurance and other debt-forgiveness policies may lead individuals to assume too much risk in personal credit decisions. In addition, cognitive errors may reinforce impulsiveness and other manifestations of poor judgment. Nevertheless, regulation on these grounds is perverse. If social insurance and other factors lead individuals to overconsume credit, the solution is to encourage individuals to internalize some of these social costs. Self-enforcing terms function much like insurance deductibles, mitigating the moral hazard of social insurance. Furthermore, the claim that individuals suffer from impulsive judgment argues in favor of precommitment devices such as security interests and wage assignments. If credit rationing is a desirable objective, then selfenforcing remedies should be subsidized rather than prohibited.

The inadequacy of the alternative justifications suggests a final possibility: lost value may be a proxy for distributional equity. The regulation of coercive collection does redistribute postdefault leverage from creditors to debtors who default. The distributional case is undermined, however, by the fact that those debtors who do not default are likely to bear much of the redistributional burden. Despite this 
problem, the illusion that causes concentrated losses to overwhelm diffused gains may cause each affected individual to prefer her end-state distribution to that of any other individual. If the criterion for distributional equity is the absence of envy, then the perception of fairness may also be the reality. The idea that policy is motivated by an aversion to concentrated losses does offer the most plausible positive account of the regulation of self-enforcing remedies.

The analysis thus seems to generate radically different implications. So long as the question is framed in terms of the prohibition of certain remedies, the normative arguments push toward all-or-nothing solutions to the problem of coercive collection. The bargaining theory approach argues against direct prohibition of consensually based remedies. On the other hand, superfairness analysis supports broad restraint on postdefault coercion. It is tempting to argue that these opposing corner solutions are not helpful in formulating more finely honed or discriminating policy prescriptions. But the binary choicecomplete prohibition or no regulation-is not an inevitable one. The all-or-nothing character of the analysis is dictated by the current preoccupation with selective prohibition.

Ultimately, however, the structural imperatives of the consumer credit transaction cannot be ignored. If the coercion associated with postdefault maneuvering is normatively undesirable, the most effective solution is to ameliorate the information deficits that generate coercive actions. Otherwise, selective regulation of particular terms will inevitably be trumped by the pressure for substitute enforcement mechanisms. So long as it is true that reciprocal commitments contribute to the regulation of consumer credit, debtors who default will be subject to contractually created coercion of one sort or another. Some commentators have suggested that parties should be encouraged to use less coercive forms of enforcement, such as income execution. ${ }^{198}$ But such indirect attempts to reduce coercion will necessarily cause an increase in the attractiveness of the economic hostage to creditors. Thus, induced breaches and other manifestations of creditor misbehavior may be the unhappy consequences of the current zeal to moderate the psychic costs of postdefault leverage through the direct prohibition of contract terms.

198. See, e.g., Whitford, The Appropriate Role of Security Interests, supra note 6, at $970-74$. 